\title{
Nuevas aportaciones al análisis arqueológico del castillo de Alcaraz (Albacete)
}

\section{New contributions to the archaeological analysis of the castle of Alcaraz (Albacete, Spain)}

\author{
Lucía Soria Combadiera \\ Universidad de Castilla-La Mancha \\ lucia.soria@uclm.es \\ José Ángel GonzÁlez Ballesteros \\ Universidad de Castilla-La Mancha \\ joseangel.gonzalez@uclm.es \\ Sonia Sanz Almendros \\ PIC-NIC (Patrimonio-Cultura-Naturaleza) \\ sonycsanz@hotmail.com
}

Fecha de recepción: 07-01-2019

Fecha de aceptación: 08-03-2019

\section{RESUMEN}

El proyecto de desarrollo rural, en el marco territorial de la Sierra de Alcaraz y Campo de Montiel, supuso el inicio de la investigación de los contextos arqueológicos de la fortaleza de Alcaraz. Este enclave fue cabeza de comarca de un importante distrito en la Edad Media. Se presenta un primer balance de los resultados obtenidos, a partir de distintos criterios de actuación. Cuestiones iniciales que pretenden establecer una serie de parámetros sobre las técnicas constructivas, el origen de la fortificación y la configuración de su recinto amurallado.

Palabras clave: fortificación, hisn, muralla, tapial, torre,

Topónimos: Alcaraz

Período: Período Almohade

\section{ABSTRACT}

The rural development project, within the territorial framework of the Sierra de Alcaraz y Campo de Montiel, initiated research into the archaeological context of the fortress of Alcaraz. This enclave was the regional capital of an important district in the Middle Ages. A preliminary evaluation of the results obtained is presented, according to different criteria. Initial questions that aim to establish a series of parameters with regards to constructive techniques, the origin of the fortification and its walled enclosure. 
Key words: fortress, hisn, wall, rammed earth, tower

Place names: Alcaraz

Period: Almohad period

\section{INTRODUCCIÓN}

El castillo de Alcaraz se sitúa en la cumbre del Cerro de San Cristóbal, de $1.028 \mathrm{~m}$ de altitud, con un perfil de cerro cónico alargado cuyo eje mayor posee una orientación de noroeste a sureste. Su ubicación le permite un control directo sobre la red de cañadas y veredas que discurren por el norte, este y oeste de la fortaleza. Dicho cerro domina hacia el este la ciudad de Alcaraz, que discurre desde de su ladera oriental hasta las estribaciones occidentales del cerro de Santa Bárbara. Alcaraz es cabeza de comarca e incluye las pedanías de Canaleja, El Cepillo, Escondite, Escorial, El Horcajo, La Hoz, El Jardín, La Mesta, Salinas de Pinilla y Solanilla. Su posición geográfica determina que sea lugar de paso obligado en un eje de comunicación estratégico a nivel nacional, el que conecta Levante con Andalucía, y el centro del país.

Dentro de las dinámicas de fomento y desarrollo de los espacios rurales a través de la financiación FEDER, se generó el proyecto "Intervención Arqueológica en la Fortaleza de Alcaraz" para la creación de un espacio temático y de uso turístico. Dicha actuación se incluía dentro de un plan de mayor escala dentro del proyecto global del Ecomuseo de la Sierra de Alcaraz y Campo de Montiel. Consistía en la recuperación y puesta en valor de las fortalezas de Alcaraz, Munera, Peñas de San Pedro, Ossa de Montiel, Lezuza y Cotillas, además de otras actuaciones concretas en los restos que se conservan en Villapalacios y Bienservida.

Figura 1. Localización de la fortaleza de Alcaraz en el marco de la provincia de Albacete y ortofotoplano

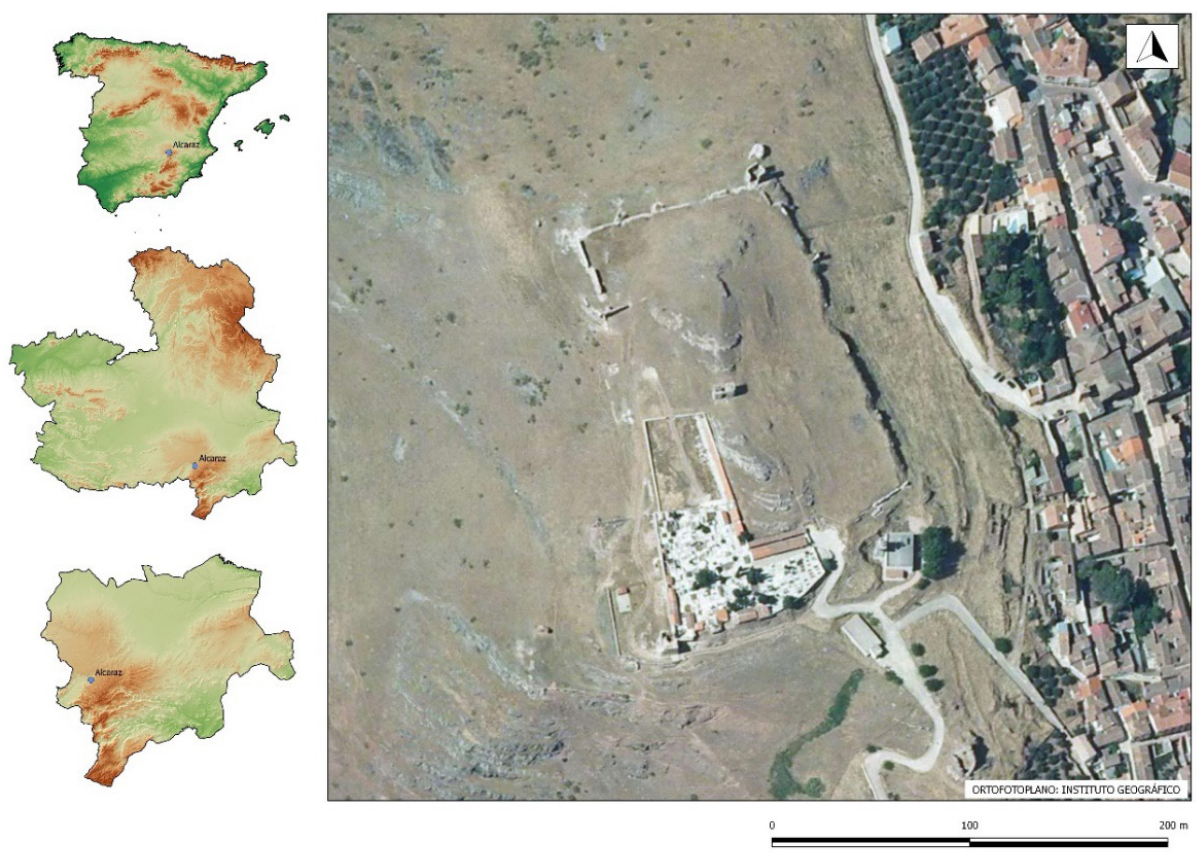

Fuente: elaboración propia. Fuente ortofotografía: Instituto Geográfico Nacional.

Este proyecto supuso la primera excavación arqueológica en la fortaleza de Alcaraz, con la ejecución de una serie de actuaciones en su entorno y en diversos puntos del recinto 
de esta fortificación ${ }^{1}$. El programa de intervenciones realizado respondió fundamentalmente a la adecuación de los espacios para su uso turístico, mediante el establecimiento de unos accesos que posibilitasen su visita, la limpieza y consolidación de los restos constructivos existentes. El análisis arqueológico se planteó a partir de cinco enfoques metodológicos:

a) Prospección del interior y límites exteriores de la fortaleza para el registro de elementos de naturaleza constructiva y de cualquier otro tipo de material.

b) Análisis paramental de varios tramos de muralla y torres mediante técnicas fotogramétricas.

c) Procesos de documentación arqueológica mediante excavación y seguimiento de los procesos de limpieza en diversos puntos de la fortificación.

d) Obtención de un ortofotoplano del castillo de alta resolución y de detalle².

e) Levantamiento planimétrico de la fortaleza.

Todos estos trabajos de campo permitieron valorar la realidad arqueológica de esta fortificación desde el punto de vista constructivo y obtener una mayor aproximación a su evolución histórica. En este caso, los datos obtenidos en el análisis paramental de un sector de la muralla de la fortificación centran este análisis ${ }^{3}$.

\section{BALANCE HISTORIOGRÁFICO}

Desde el punto de vista historiográfico, el conocimiento de la fortaleza se encuadra en tres temáticas. La primera afecta al origen del actual emplazamiento, las primeras referencias de Alcaraz y su relación con el yacimiento de El Santo, lugar que las fuentes escritas denominan Alcaraz el uiejo en 1239 (Pretel, 2008: 244, núm. 8). En segundo lugar, el estudio sobre la Edad Media alcaraceña ha sido tema central del medievalista Pretel (2004, 2008, 2013, 2014 y 2015). Finalmente, los estudios arqueológicos en superficie sobre la fortaleza llevados a cabo por el arqueólogo Simón (2011: 222-234, 2013 y 2015) y el estudio de sus principales elementos.

1 Hasta este momento, la única actuación arqueológica desarrollada en su interior fue realizada por la empresa Carpetania Integra con motivo de unas obras de ampliación del cementerio municipal localizado en el interior de la fortaleza.

2 Dichos trabajos se realización mediante vuelo de dron y estuvieron a cargo de la empresa DRAKKAR CONSULTORES Esta misma empresa y de manera paralela al desarrollo del proyecto realizó en el año 2015 el análisis paramental de la torre 9 referenciada como torre de Morcil, trabajo por el momento inédito y al que agradecemos que nos hayan facilitado la información.

3 Para el conocimiento de las diferentes variantes de la técnica constructiva del tapial en al-Andalus nos hacemos eco de las propuestas metodológicas presentadas por Malpica (1998) y Martín (2009) para el caso de Granada; Graciani y Tabales (2008) en las formas del tapial en el caso de Sevilla; los trabajos de Márquez y Gurriarán (2003, 2008 y 2012) sobre los procesos constructivos en el ámbito de Extremadura; Azuar (2004) y Soler (2009) para el caso de Sharq al-Andalus; Gil y Maldonado (2015) aplicados al estudio de las fortificaciones con la técnica de tapial en la mitad norte peninsular; Cobos, Castro y Canal (2012) para el caso de los encofrados en fortificaciones del reino de León. Esta actualización de propuestas analíticas, tanto desde la perspectiva taxonométrica como de las cadenas operativas en los procesos constructivos, permite una relación descriptiva de la técnica del tapial en este contexto constructivo. 
Figura 2. Delimitación de la planta de la fortaleza de Alcaraz y restos constructivos en superficie. En diferentes colores los sectores de trabajo realizados durante la prospección de campo

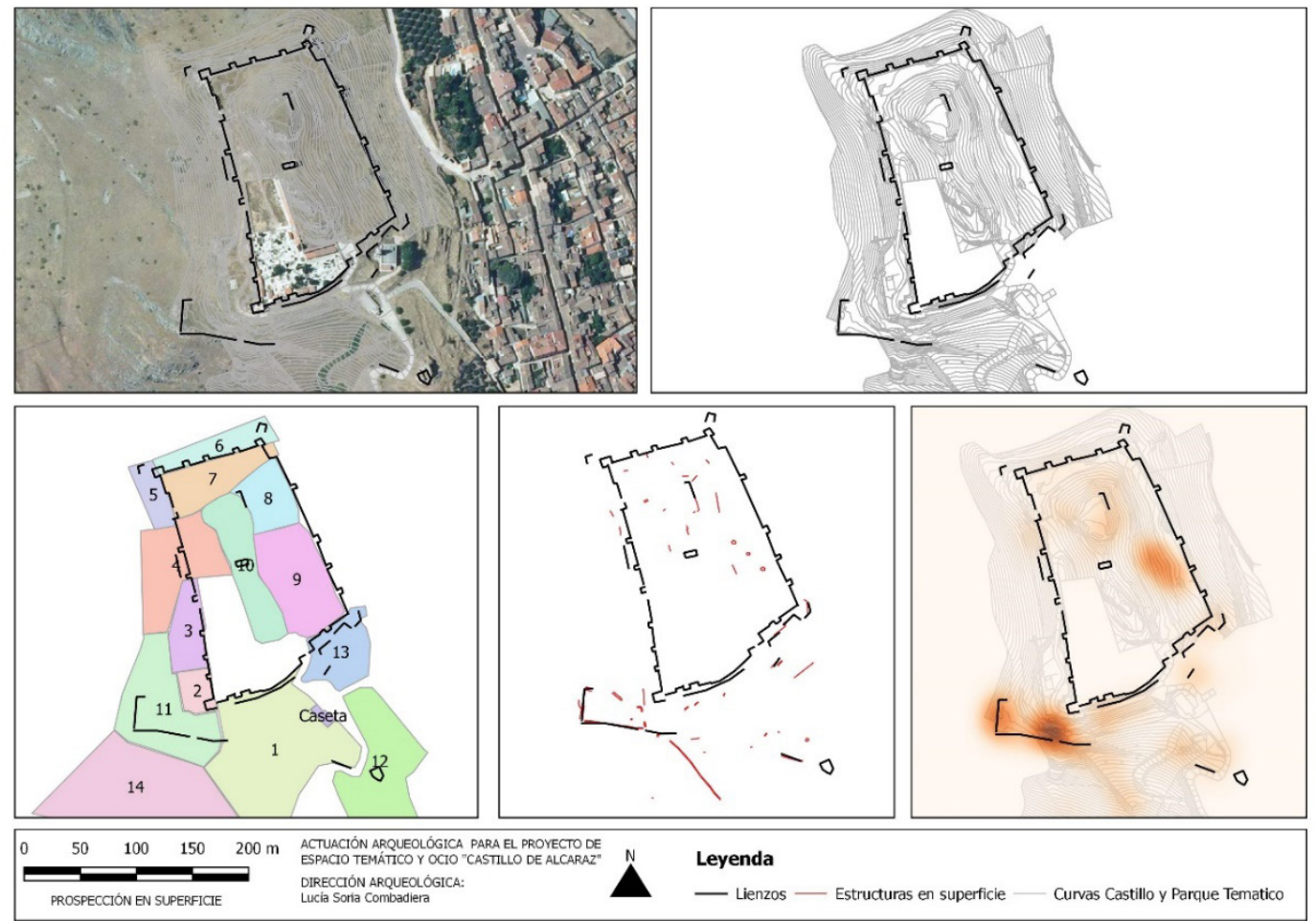

Fuente: elaboración propia.

Torres Balbás (1976: 647-648 y 670) llevado por la delimitación de la planta de tendencia rectangular se postuló sobre un origen califal de este recinto. También Pavón Maldonado (1999: 130 y 133) recoge este dato cronológico, aunque establece una nueva propuesta para los siglos XI y XII. Como ya se ha apuntado en otras ocasiones, parece cuestionable establecer a este periodo todo el conjunto por la técnica constructiva actualmente visible (Simón, 2013: 58; Pretel, 2008: 24; 2014: 283). Esta observación ya la acentuó el propio Amador de los Ríos (1917: 410-411) a principios del siglo XX, al considerar la ausencia de restos anteriores al periodo almohade.

Con toda probabilidad, la presencia de poblamiento en época emiral y califal esté en relación con el yacimiento de El Santo, situado a 4'2 km de distancia. El cambio de emplazamiento y toponimia estaría vinculado a uno de dos procesos posibles entre los siglos X y XI: el asentamiento territorial del califato como programa estatal, o el resultado de los procesos de afianzamiento de las taifas emergentes tras la desintegración del califato omeya.

La conformación del califato y la victoria de Abd al-Rahman III supuso el sometimiento de una serie de territorios sublevados, manteniendo a las elites que estaban de su parte. Desde Córdoba se potenciaron nuevas fortalezas, cuyo principal fin fue el de mantener el control sobre el territorio y las vías de comunicación. Esta hipótesis podría dar respuesta al cambio de emplazamiento de El Santo al cerro de San Cristóbal, como una fundación ex novo mediante la construcción de un hisn para ejercer un cierto control de un territorio poblado de alquerías o como mecanismo defensivo en zonas turbulentas (Malpica, 2009: 117-118). Esta implantación estaría, tal vez, en relación a una fortificación limitada a lo alto de la cumbre del cerro de San Cristóbal, del que no hay datos arqueológicos. Recientes investigaciones establecen este posible traslado desde El Santo al asentamiento en el cerro 
de San Cristóbal a la política califal por el sometimiento de territorios sublevados (Simón y Hernández, 2016: 69).

Con respecto a la segunda opción, durante la desmembración del califato y primeras taifas del siglo XI, este territorio se encuadró en un primer momento bajo el control de Ios Banu Di-I-Nun, familia bereber de la tribu hawwara que reinó en la Taifa de Toledo. Posteriormente basculó a la taifa de Murcia, a la de Denia y finalmente a la de Sevilla (Simón, 2015: 75). Este periodo de movimientos fronterizos pudiera ser el origen de la fortaleza de Alcaraz por parte de alguno de estos poderes en el control del territorio.

Figura 3. Vista de la vertiente noroeste del cerro de San Cristóbal donde se emplaza la fortaleza

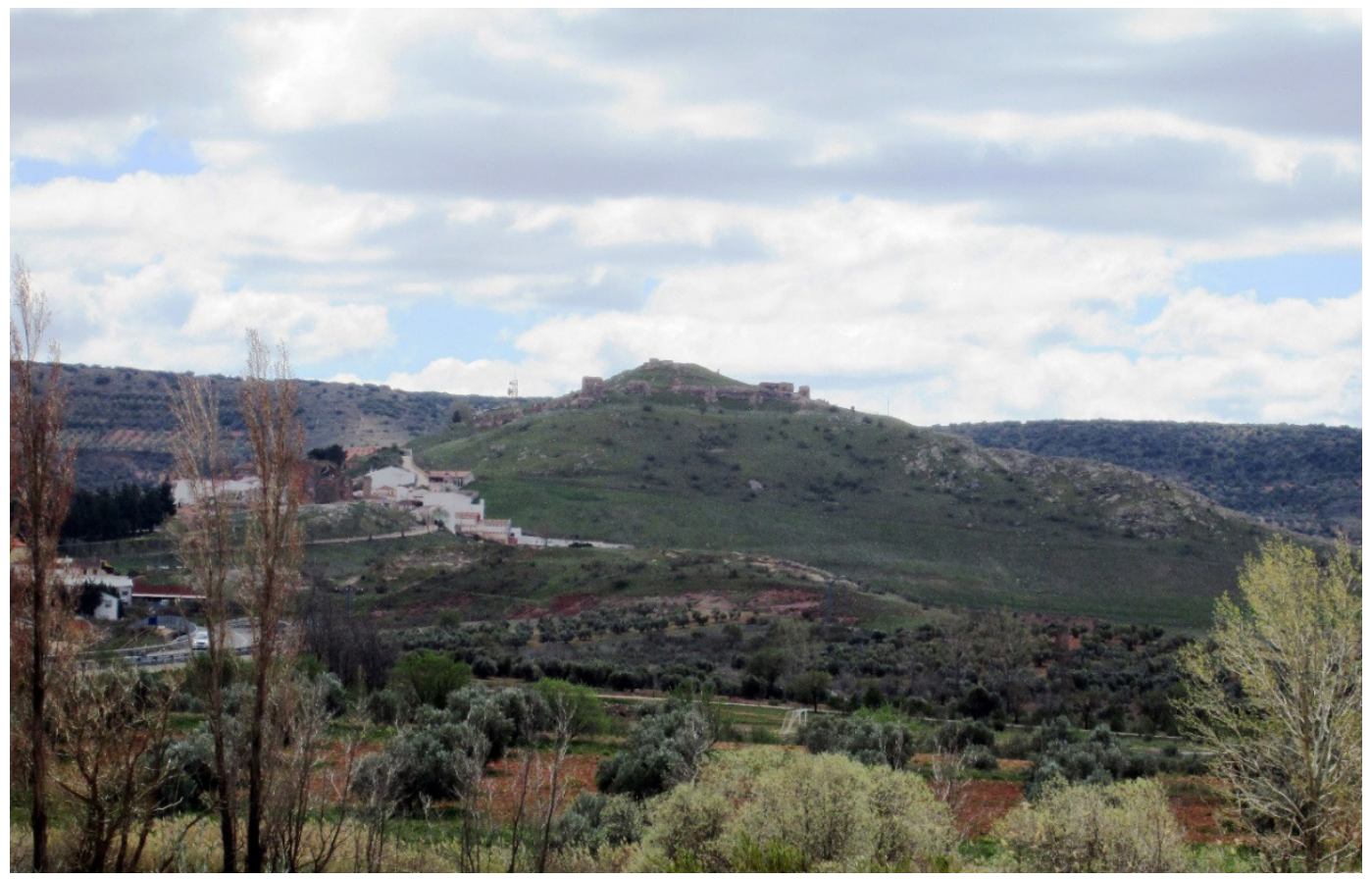

Fuente: fotografía de los autores.

La primera noticia documental de la fortaleza de Alcaraz se establece en el segundo cuarto del siglo XII, durante el dominio almorávide. Alfonso I el Batallador desarrolla en 1125-1126 una serie de incursiones hacia territorio almorávide, donde las tierras de Alcaraz formarían parte de su recorrido. En estos momentos se menciona un intento de fortificación por parte de tropas cristianas infiltradas en territorio islámico (Pretel, 2013: 47).

En el año 1126 el emir almorávide Tasufín atacó esta pequeña fortificación o campamento como respuesta, recuperando esta plaza y una serie de castillos que estarían adscritos a Alcaraz y que probablemente son los que formaría la frontera o Tugur al-Kursi, que menciona el geógrafo al-Zuhri (Pretel, 2008: 36). Punto clave en las rutas orientales entre Jaén y Cuenca.

Bajo el dominio del emirato de Ibn Mardanish en el siglo XII, tras la desmembración del dominio almorávide, el control territorial lo ejerció Ibrahim Ibn Hamusq. Un visirato constituido en torno a Segura de la Sierra y que englobó a la propia Alcaraz (Frey, 2014: 55). Este punto se convirtió en un lugar estratégico para el control del paso entre las sierras de Jaén y Segura, la llanura manchega y las tierras de Murcia como cabeza de un tagr o distrito fronterizo del reino mardanisí. Como el resto de zonas de control de paso, fue un punto de conflicto en la lucha entre los almohades y el reino de Castilla con sus aliados como el emirato del Rey Lobo (Pretel, 2008: 39). Dentro de esta dinámica, la fortaleza fue 
donada a manos castellanas en el periodo 1169-1172 para controlar el camino oriental de Andalucía.

La caída del emirato mardanisí propició un cambio en el control del territorio a partir del año 1172. Se produjo el retorno a dominio musulmán con su conquista por parte del califa almohade Abú Yaquf Yusuf y su yerno Ibn Hamusq, que certificó un acto de rebeldía y una nueva alianza en contra de Ibn Mardanish. Sobre este episodio Ibn Sáhib alSalát, principal cronista de los almohades, describe que encontraron "un castillo elevado dispuestos a limpiarlo de la infidelidad, porque Ibn Mardanish lo había dado a cristianos" (Pretel, 2013: 50). A partir de este momento queda bajo el control del califato almohade con alguna noticia confusa sobre una posible breve ocupación cristiana en el año 1197 (Pretel, 2014: 286).

El geógrafo e historiador del siglo XV al-Himyari menciona el hisn al-Karas como parte de la Cora de Jaén y narra el episodio de la toma de Alcaraz por parte de Castilla (Pacheco, 1981). De su descripción destacan dos elementos: la denominación como hisn y la alusión a las murallas del emplazamiento.

La conquista, realizada por Alfonso VIII de Castilla en 1213, fue parte de ese impulso que generó la victoria de las Navas de Tolosa, un año antes, en la conquista de la sierra del Segura. Estos episodios se identifican como un epílogo de esa batalla ${ }^{4}$.

\section{NUEVOS DATOS PARA EL ESTUDIO DE LA FORTIFICACIÓN ANDALUSÍ DE ALCARAZ}

Destaca la configuración de un gran recinto de planta rectangular de $210 \mathrm{~m}$. de Norte a Sur, $115 \mathrm{~m}$. de este a oeste, con una superficie de 3,99 ha. En su estado de conservación actual sobresalen dos tipos de fábricas (Simón, 2011: 222-232): el tapial y la mampostería irregular ${ }^{5}$ trabada con mortero de cal. De forma minoritaria aparece el sillar y sillarejo en los elementos suntuarios de edificios singulares, como el interior de la Torre del Obispo y la Iglesia de Santa María El análisis del espacio constructivo puso de relieve la división en cinco sectores (Simón y Hernández, 2016: 71):

- Fortificación de la cumbre representada por los restos de dos torres.

- El recinto amurallado que actualmente es la base de la fortificación.

- Defensas exteriores, como torres y murallas.

- Restos de un posible edificio en el sector suroeste.

- Los arrabales localizados en la ladera meridional y oriental del cerro.

De la fortificación en la cumbre del cerro se conservan dos torres unidas entre sí por la parte superior, que se interpretan como una puerta de acceso al interior de un recinto. Construidas con tapial hormigonado, se plantea su origen constructivo bajo el control de Ibn Mardanish, el rey Lobo (1147-1172). Según algunas hipótesis, seguiría el modelo de las construcciones que se generalizan en la península con la llegada de las dinastías africanas y cuyas principales fortalezas estatales se encuentran en las obras de amurallamiento de la ciudad de Murcia, el castillo de Monteagudo, el de Larache, el palacio fortificado de El Castillejo de Monteagudo y los fortines inacabados de La Asomada y El Portazgo (Simón y Hernández, 2016: 71-73). Este recinto primitivo ocuparía una superficie de $3.600 \mathrm{~m}^{2}$ y

4 Sobre los aspectos de su conquista nos remitimos a los trabajos de Pretel (2008 y 2014).

5 En nuestras observaciones sobre estas fábricas adscritas a periodo bajomedieval cristiano consideramos que se tratan de encofrados de mampuestos. 
podría ser el hisn de los siglos XI y XII que Ibn Mardanish cedió a los cristianos junto a Vilches (Simón, 2013: 64-65; Simón y Hernández, 2016: 74 y 77).

Figura 4. Localización del tramo analizado

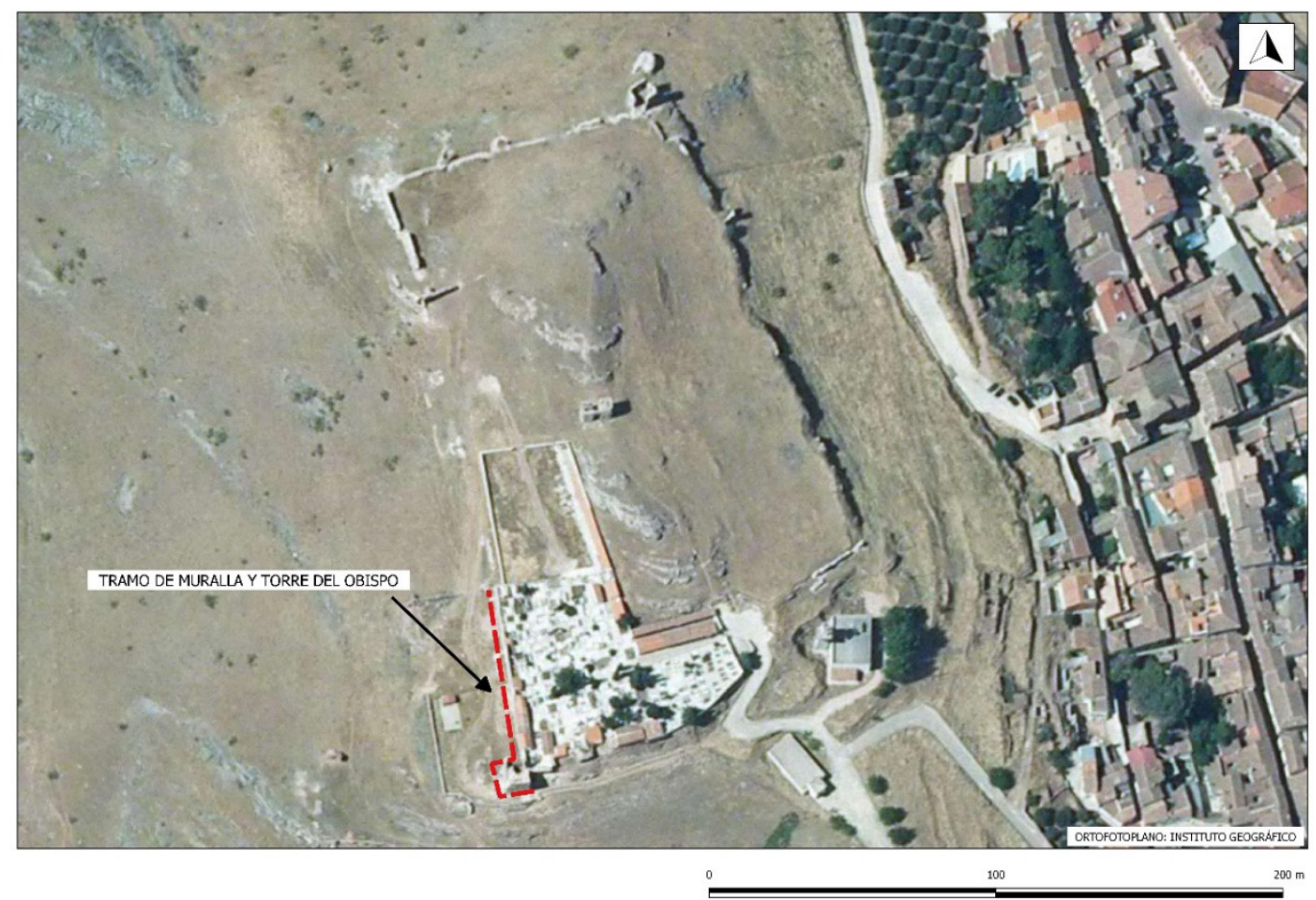

Fuente: Elaboración propia. Fuente ortofotografía: Instituto Geográfico Nacional.

Figura 5. Vista del frente occidental de la fortaleza de Alcaraz

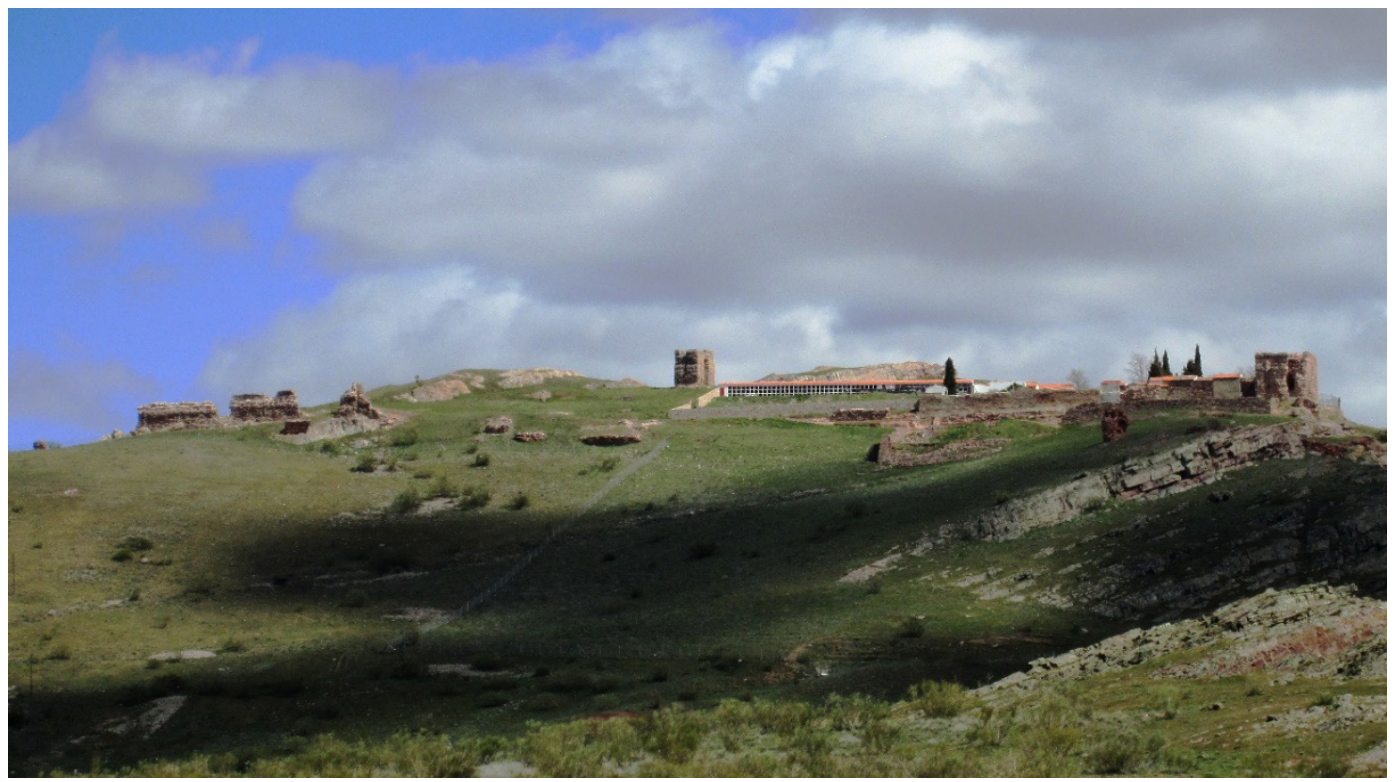

Fuente: fotografía de los autores.

El recinto de tendencia rectangular se compone de torres esquineras y torres menores a cada lado de las murallas, constatándose dos accesos: uno en la parte noroeste, constituido por una puerta en codo bajo una torre rectangular, cuyo diseño y características 
son propios de finales del siglo XII e inicios del siglo XIII. El otro acceso se interpreta en el centro del flanco sur que, por el momento, ha quedado oculto o destruido por las tapias del actual cementerio, por lo que no deja de ser una hipótesis. Otro elemento que se localiza en la parte que ocupa el cementerio es el de un aljibe excavado en la roca. Por otro lado, se interpreta la presencia de portillos situados junto a la torre noroeste, que darían acceso a los arrabales de la ladera oriental. El recinto fortificado posee restos de un antemural o barbacana, especialmente en la parte de las murallas occidental y meridional, no apreciándose actualmente en la septentrional y en la oriental (Simón, 2013: 65-67).

Los trabajos arqueológicos efectuados se centraron en el estudio de un tramo de unos $98 \mathrm{~m}$. longitudinales de la muralla occidental del recinto mayor de la fortaleza, entre T-2 y L-18 (Fig. 4) ${ }^{6}$. Sobre este tramo sólo se practicó una actuación de limpieza y de retirada de escombros recientes, al actuar la zona como un pequeño vertedero. Esta retirada permitió definir partes de la muralla mejor conservadas que han aportado nuevos elementos de análisis sobre sus tapias.

En cuanto a la estructura de la fábrica, se trata de un tapial monolítico, muy característico en el conjunto de fortificaciones y recintos amurallados del periodo almohade, sobre todo en sus primeras etapas. En función de los componentes y de su disposición se establece la variante del tapial de cal y canto o calicantos, en la que los mampuestos del relleno del encofrado se disponen formando tongadas o hiladas. El mortero presenta un proporción variable de cal, con piedra del terreno, actuando como revestimiento y ocultando la piedra ${ }^{7}$. Se observa esta disposición de los mampuestos del interior del cajón debido a la pérdida de la costra exterior como consecuencias de diversos factores.

El grosor de los muros que componen la muralla de la fortaleza se calcula en 1,5 m. No se llega a constatar en ningún punto la anchura real, ya que la erosión y la reutilización de estas murallas han afectado enormemente a su integridad. En los restos actualmente visibles, se conserva la mitad de su anchura original marcada por una de sus caras 0 el núcleo de la estructura. A través de taquimetría, se ha calculado en tramos donde se conserva el límite de la cara interior (L-18) y en tramos donde se conserva la cara exterior (el resto de lienzos).

6 La referencia de sectorización se establece a partir de la realizada por Simón (2011: 222-234).

7 Disentimos de la definición de tapial de mampostería como técnica propuesta para la fábrica de este recinto de la fortificación establecida por Simón o el de mampostería hormigonada establecida por Pavón. La combinación de los términos tapial y mampostería lleva a una clara confusión patente en la interpretación arquitectónica en procedimientos de restauración. La piedra o mampuesto es un componente o material utilizado, mientras que la mampostería expresa un procedimiento o técnica de construcción en albañilería completamente diferente al tapial. El hecho de que en la colocación de los mampuestos estén dispuestos en el interior del encofrado en hiladas, no lo convierten en mampostería, sino en un procedimiento más de la propia técnica del tapial o de un sistema de encofrado. En los tramos donde se conserva la superficie de la tapia no se aprecia esta disposición. Su degradación hace que el núcleo de piedras asome y que se confunda con esta técnica, cuestión que se ha puesto de manifiesto en el estudio de numerosos análisis de fortalezas andalusíes peninsulares en la que se emplea el tapial como técnica constructiva. En la clasificación de tapiales en el área de Sharq al-Andalus, Soler (2009: 1362) establece como tipo 2.1a la tapia de argamasa con mampuestos colocados con un orden de forma irregular ordenados por hiladas horizontales, señalando la técnica de mampostería para la construcción de zócalos de apoyo o cimentación, diferenciando de este modo ambas técnicas constructivas. La idea de mampostería encofrada empleada por Cobos et al. (2012: 118) o Gil y Maldonado (2015: 4) se puede aplicar de una manera más precisa. Aunque otra alternativa es "encofrado de mampuestos", cuando se observa el predominio de la piedra sobre el mortero y cuyo aparejo deja la intención de ver esos mampuestos sin un recubrimiento que los oculte. Martín (2001-2002) establece y define claramente la diferenciación de las dos técnicas constructivas en el periodo andalusí a partir del estudio del valle del Zenete en la provincia de Granada. 
El grosor de las torres está en relación a su tamaño de base y altura. Según su disposición se establecen tres categorías:

- Torres esquineras, las de mayor volumen. Aunque debido a su estado de conservación no se han podido establecer mediciones reales de la anchura original del cajón, estableciendo la posibilidad de unas dimensiones entre 1,3 y 1,5 m. en función del módulo de planta.

- Torres del frente de muralla, con una variabilidad morfológica en cuanto a anchura de la parte frontal y de los laterales, aunque siempre menores que las esquineras (1,15 y 1,30 m. de anchura).

- Torre-Puerta, con ciertas similitudes dimensionales con respecto al perímetro de las torres esquineras, con un cajón en la parte interior que alcanza los $2 \mathrm{~m}$. de anchura.

Figura 6. Alzado del tramo de muralla occidental intervenido del castillo de Alcaraz

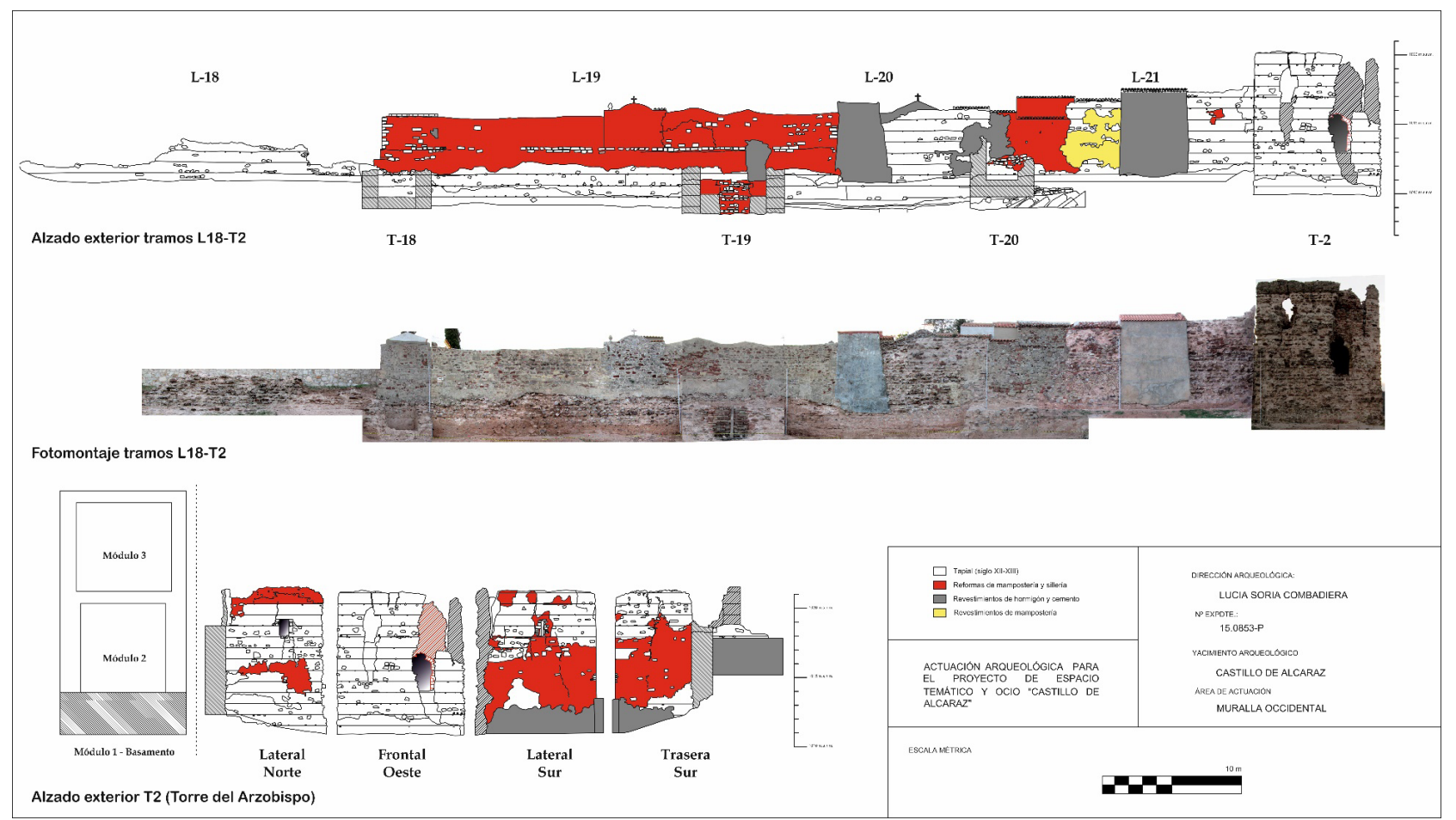

Las torres esquineras se componen de un basamento macizo y dos alturas huecas. La anchura de cajón de 1,5 m. de la muralla, plantea como opción más posible el empleo de media aguja. En las murallas con espesores medios de 1,30 m. y, sobre todo en las torres, las agujas no atraviesan todo el muro (Martín, 2001-2002: 187). Se trata de cajones continuos con tramos que oscilan entre 13 y $18 \mathrm{~m}$. de longitud. La única junta vertical se identifica en el lienzo 19 (L-19), en la tercera bancada, que es el lienzo de mayor longitud. Por las inspecciones realizadas en el resto de la fortaleza, la longitud de $14 \mathrm{~m}$. es la predominante en el resto de cortinas. Los datos obtenidos, a partir de las torres existentes en el resto del conjunto fortificado, establecen una relación de 19-20 m. o 14-17 m. de longitud de cortina. 
Figura 7. Disposición de bancadas en L-19

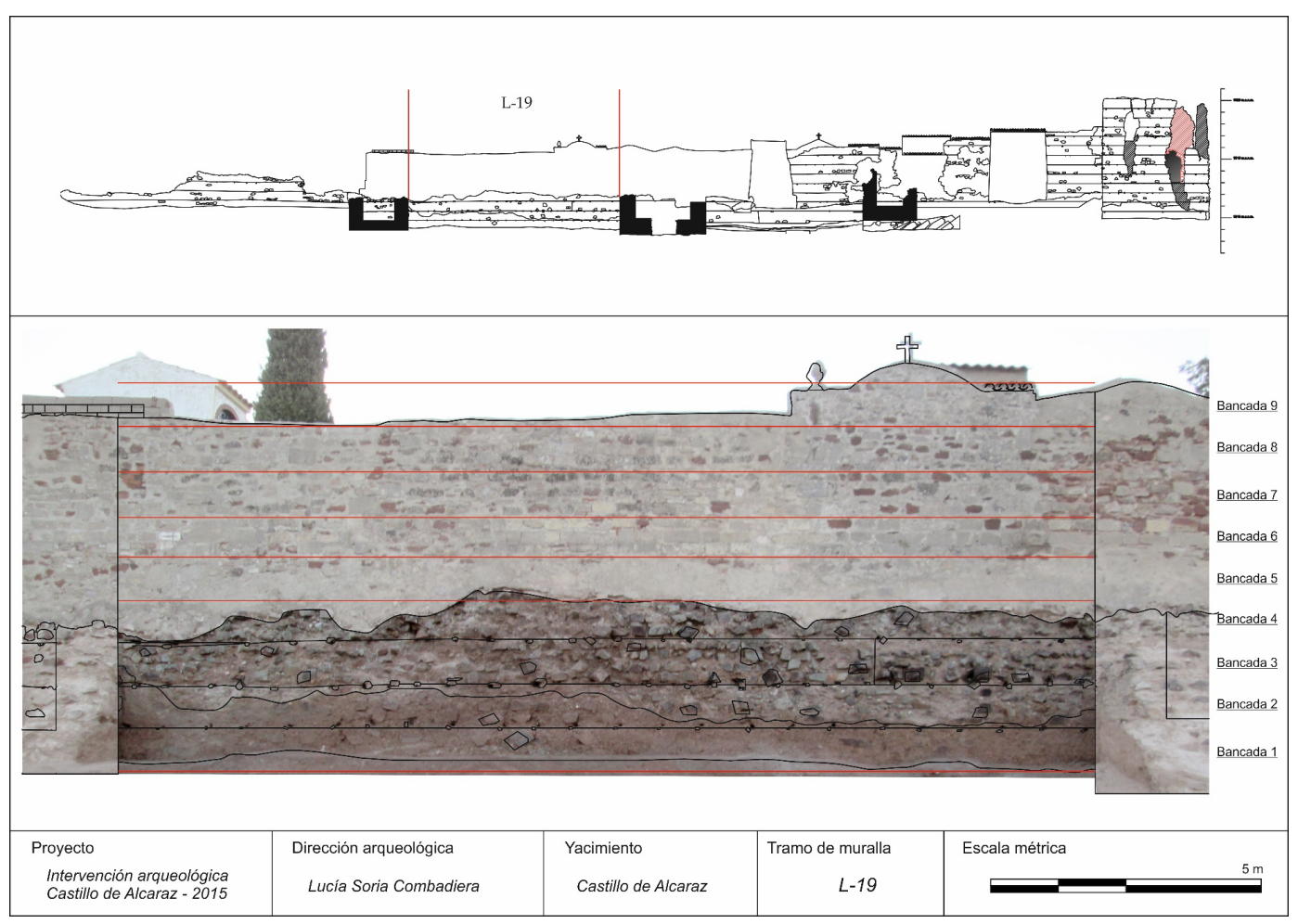

Figura 8. Disposición de bancadas en L-20

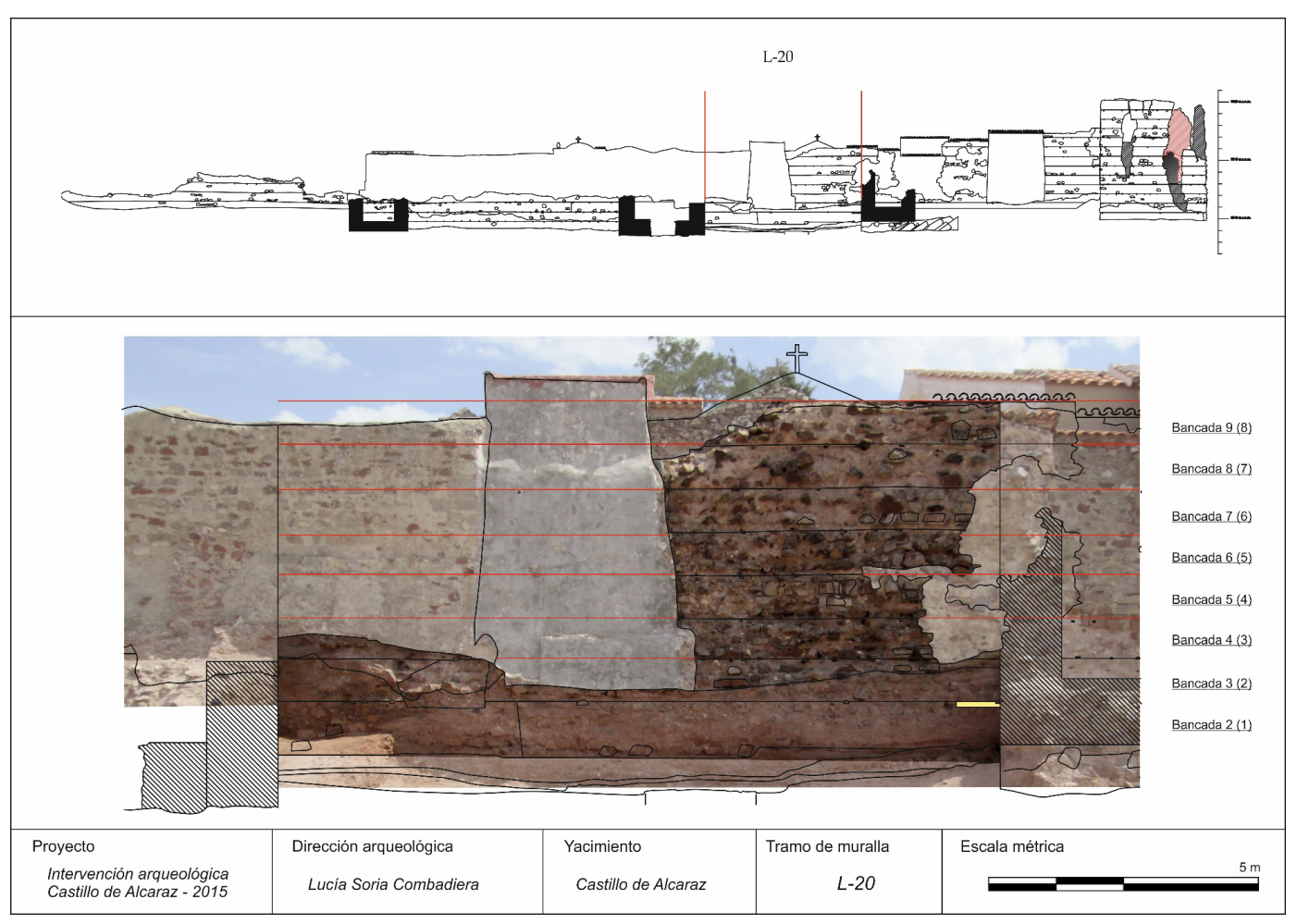


Figura 9. Disposición de bancadas en L-21

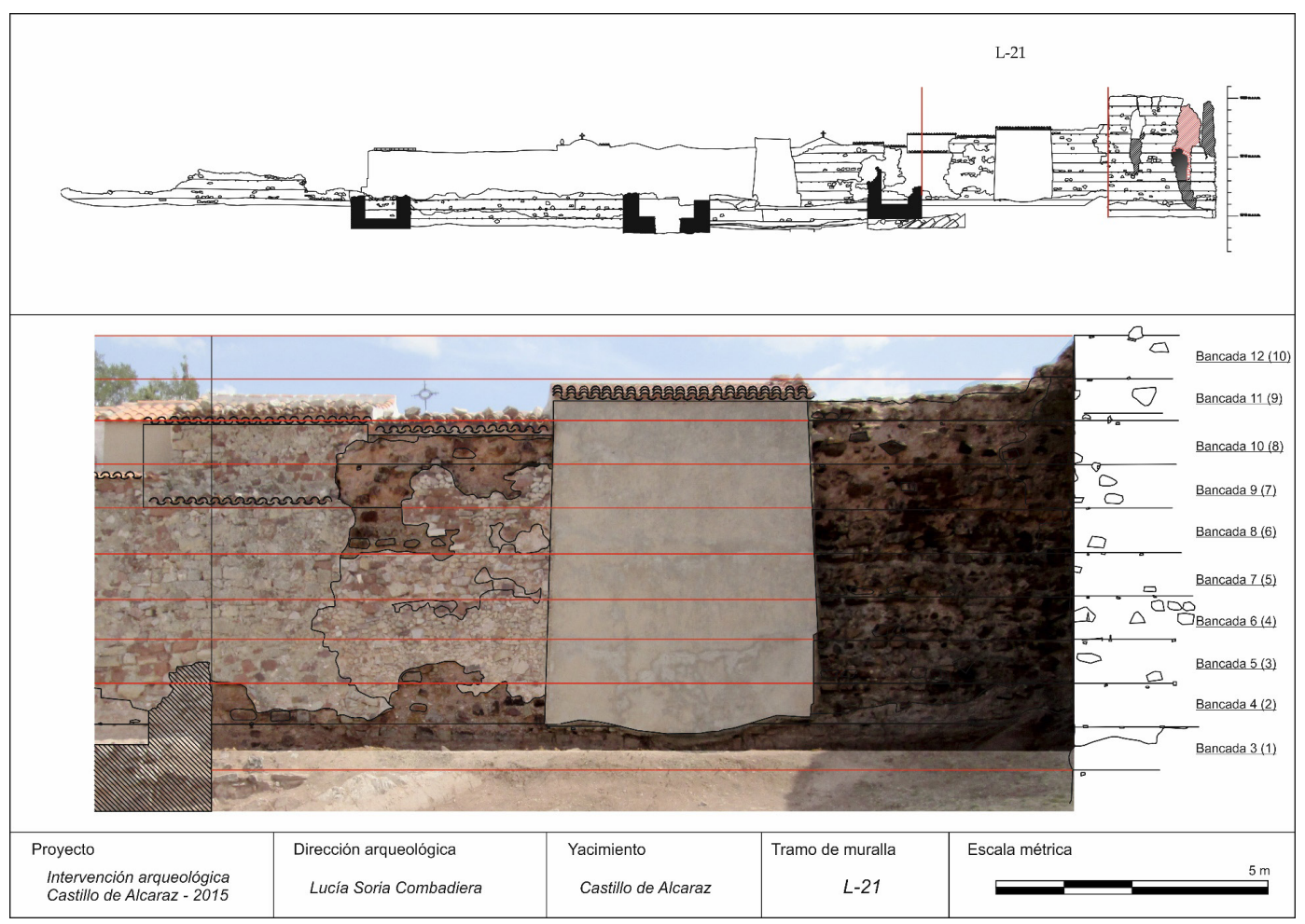

Figura 10. Disposición de bancadas en T-2

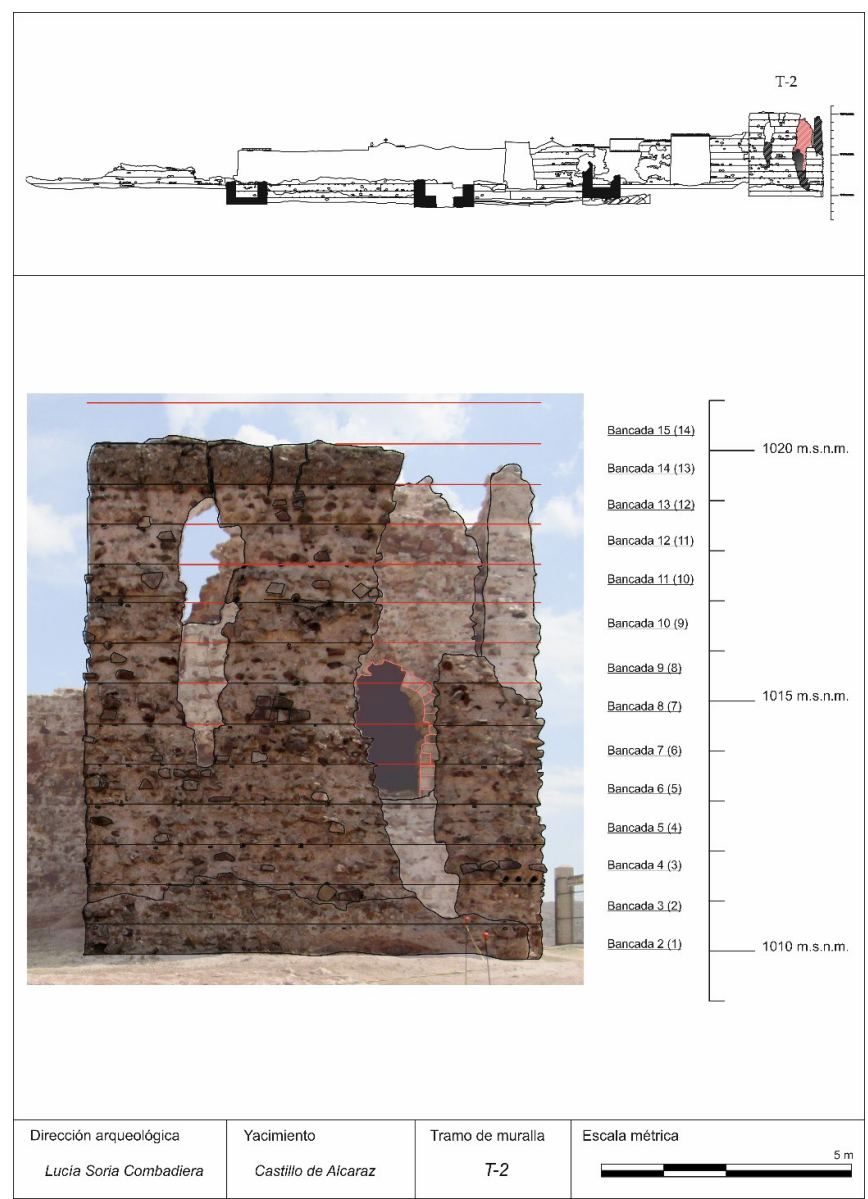


La altura del cajón en el nivel de junta ofrece una altura de $80-85 \mathrm{~cm}$. en función de la calidad del apisonado y las rebabas del mortero. Esta variación se relaciona con el proceso de ejecución, con el afloramiento de piedras en la parte interior de asiento de la bancada, o bien, con el modo de trabajo de colocación y asiento en el mortero. La medición señalada se relaciona con el sistema preferente de época almohade, el codo mammuní, de 45-47,14 cm., aplicándose al molde de encofrado, no a la altura de argamasa, por lo que se relaciona con dos codos mammuníes.

Cada tablero estaba formado por cuatro tablas y según las registradas en T-18 tienen $20 \mathrm{~cm}$. de altura. El número de tongadas en el interior de cada cajón es de cuatro, lo que viene a coincidir con la altura de cada tabla. Este hecho indica una relación entre la altura de cada tabla del cajón con la disposición de las tongadas del relleno en la organización del trabajo, por lo que se utiliza esta disposición como medida de referencia en la ejecución del cajón.

El sistema constructivo de esta parte de la fortificación viene a definir un módulo bajo (80-85 cm.). En el Suroeste de la península, las modulaciones predominantes en las fábricas almohades son de módulo alto $(85-95 \mathrm{~cm}$.). Aunque se constatan alturas menores a los 85 $\mathrm{cm}$. en los tapiales del Castillo de Guillena $(75 \mathrm{~cm}$.), las Murallas de Niebla y la Torre de San Antonio (80 cm.). En muchos de los casos considerados de datación incierta el módulo predominante es bajo (Graciani y Tabales, 2008) ${ }^{8}$.

Tabla 1. Relaciones métricas de los diversos tramos de muralla y torres

\begin{tabular}{|c|c|c|c|c|c|c|c|c|}
\hline \multicolumn{9}{|c|}{ Medidas establecidas tras las actuaciones del año 2015} \\
\hline $\begin{array}{l}\text { Referencias } \\
\text { elementos }\end{array}$ & L18 & T18 & L19 & T19 & L20 & T20 & L21 & $\mathrm{T} 2$ \\
\hline $\begin{array}{l}\text { Altura } \\
\text { cajón } \\
(\mathrm{cm})\end{array}$ & 80 & 80 & 80 & 80 & $80-100$ & 80 & 80 & 80 \\
\hline $\begin{array}{l}\text { Anchura } \\
\text { cajón } \\
\text { (cm) }\end{array}$ & 1,5 & 1,15 & 1,5 & 1,32 & 1,5 & 1,15 & 1,5 & 1,5 \\
\hline $\begin{array}{l}\text { Longitud } \\
\text { muralla } \\
(\mathrm{m})\end{array}$ & Ind. & & 18 & & 13,4 & & 15,8 & \\
\hline $\begin{array}{l}\text { Anchura } \\
\text { frontal } \\
\text { torre }(m)\end{array}$ & & 5 & & 7,35 & & 4,6 & & 9,15 \\
\hline $\begin{array}{l}\text { Altura } \\
\text { conservada } \\
\text { (m) }\end{array}$ & 2,93 & 2,38 & 3,05 & 2,4 & 6,48 & 1,45 & 6,87 & 10,3 \\
\hline $\begin{array}{l}\text { No bancadas } \\
\text { conservadas }\end{array}$ & 4 & 4 & 4 & 5 & 8 & 2 & 10 & 14 \\
\hline
\end{tabular}

Fuente: elaboración propia

El cajón continuo o corrido supone una novedad de las construcciones almohades a finales del siglo XII. Este hecho mejora el rendimiento de ejecución, al ahorrar tareas y

8 Los tapiales de la Torre de la Dehesilla, el Castillo de las Guardas, la Hacienda de Quintos y el Castillo de Hornachos presentan $80 \mathrm{~cm}$. de altura. 
agilizar el proceso, y además facilita el armado, el vertido del material y el apisonado de la argamasa, esencialmente importante en periodos de cierta celeridad defensiva (Canivell y Graciani, 2015: 11), lo que concuerda con el proceso constructivo de la fortificación de Alcaraz.

Sobre esta modulación existe una excepción: en el caso del lienzo L-20, la primera bancada de asiento y cimentación mide $1 \mathrm{~m}$., aunque no de manera uniforme ya que se constata un quiebro para adaptarse a la base geológica. Este módulo se observa en algunos muros del Alcázar Mayor de Murcia, levantados entre finales del siglo XII y principios del siglo $\mathrm{XIII}$, donde las tapias inferiores miden $1 \mathrm{~m}$. y las superiores miden $80 \mathrm{~cm}$. En el Castillejo de Monteagudo (Murcia), de obra mardanisí, se indica este mismo suceso, con modulaciones en la base de $1 \mathrm{~m}$., las intermedias de $80 \mathrm{~cm}$. y la superior de $70 \mathrm{~cm}$. (Navarro y Jiménez, 2011: 104).

No se han constatado secciones circulares de los agujales o mechinales, dividiéndose en:

- Planas o rectangulares (R): de 7 a $8 \mathrm{~cm}$. de largo y de 2 a $3 \mathrm{~cm}$. de alto.

- Semicirculares (Sc): de $6 \mathrm{~cm}$. de diámetro.

- Cuadrangulares $(\mathrm{Cu})$ : de $5 \mathrm{~cm}$. por $4 \mathrm{~cm}$. de lado.

La aguja plana suponía un ahorro de material, facilitaba el acoplamiento y nivelación del encofrado y permitía perforar su tabla para recibir un costal. Resulta evidente el empleo mayoritario de estos listones rectangulares en el montaje de los encofrados, aunque con presencia de otro tipo de secciones que, por el momento, no postulan ninguna relación en la cadena constructiva de este sistema.

Figura 11. Relación de sección de mechinales en L-19

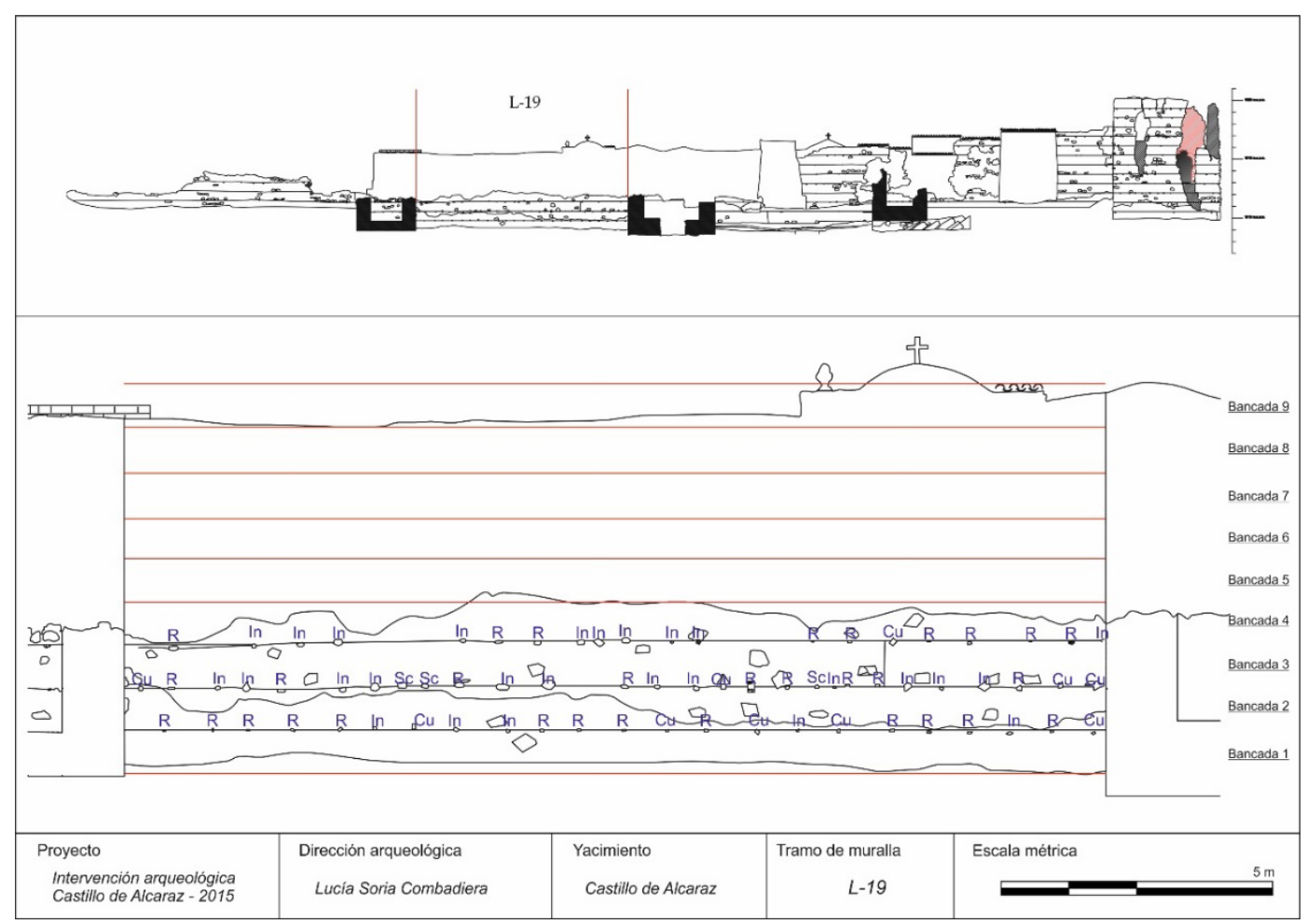


Tabla 2. Tabla de frecuencias del tipo de mechinal

\begin{tabular}{|c|c|c|c|c|c|c|}
\hline & \multicolumn{7}{|c|}{ L-19 (18 m) } \\
\hline & $\begin{array}{c}N^{\circ} \\
\text { Total }\end{array}$ & $\mathrm{C}$ & $\mathrm{Sc}$ & $\mathrm{Cu}$ & $\mathrm{R}$ & Ind \\
\hline Bancada 2 & 23 & 0 & 0 & 5 & 13 & 5 \\
\hline Bancada 3 & 28 & 0 & 3 & 4 & 9 & 12 \\
\hline Bancada 4 & 20 & 0 & 0 & 1 & 9 & 10 \\
\hline
\end{tabular}

Relacionado con el proceso de ejecución constructiva, en el caso de la bancada 2, la línea de agujales rectangulares ofrece, en ocasiones, una disposición inclinada. Este hecho viene a incidir en el sistema de andamiaje y su organización, o también puede relacionarse con el proceso acelerado de estos encofrados de madera, como se aprecia en algunas bancadas de L-20 y L-21.

Respecto a la separación de agujas, se observa una distribución irregular tanto en el eje vertical entre bancadas, como en el propio eje horizontal de desarrollo de la bancada. Este hecho implica una distribución desordenada y sin una secuencia clara (Fig. 11). La posición de la aguja con respecto a la junta de unión es irregular, observándose una colocación tanto abajo, como arriba o en posición central con respecto a la línea de unión entre bancadas, sin que obedezca a un patrón establecido (Fig. 12). Esta circunstancia tiene que ver con una ejecución apresurada y, tal vez, por una mano de obra poco cualificada.

Figura 12. Detalle de junta entre cajones en L-19. Se observan disposiciones superiores e inferiores de los agujales en la junta de unión entre filas de cajones

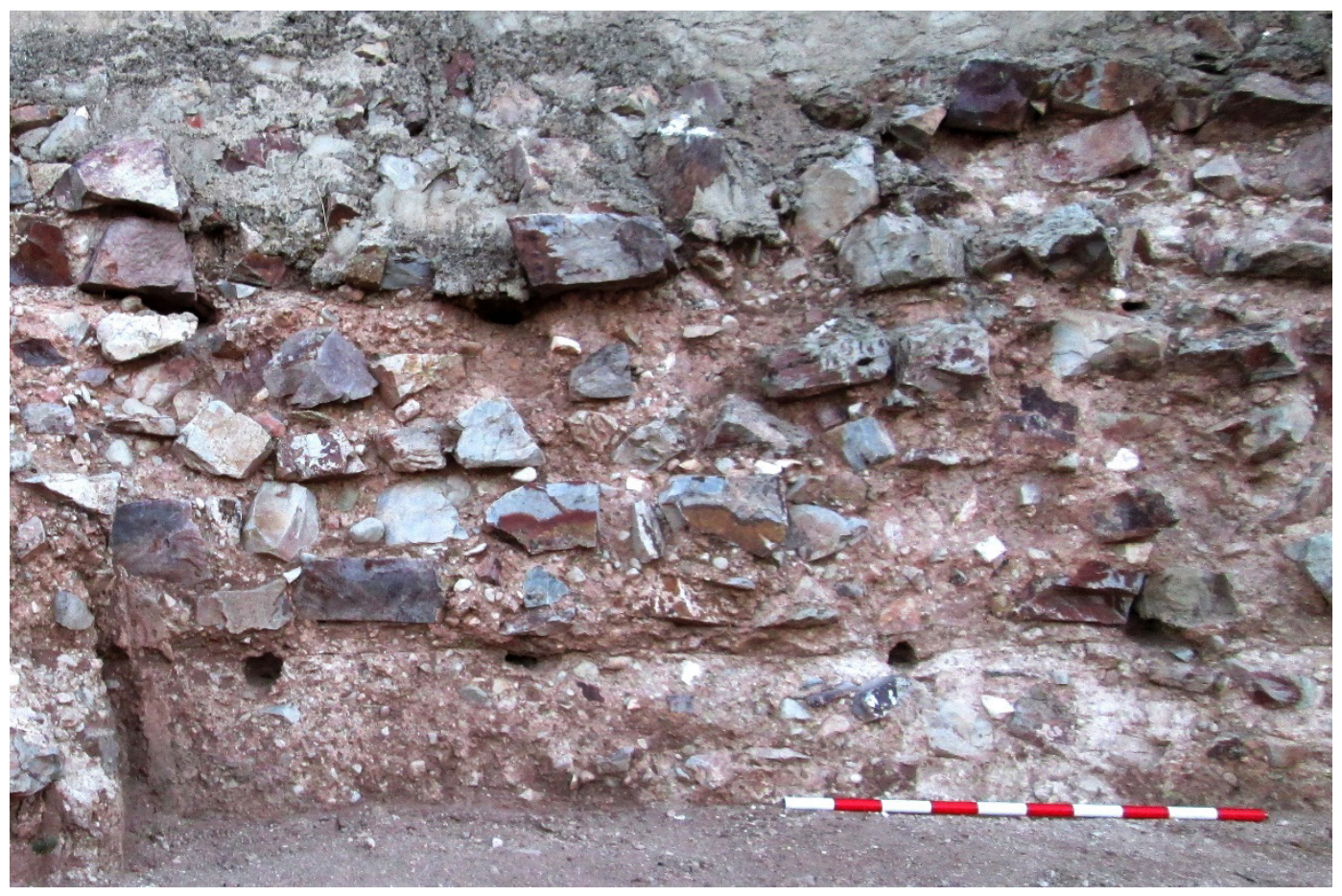

Fuente: fotografía de los autores. 
Estos mechinales o agujales presentan algunos casos de remate de piedra (Fig. 13). Se aprecia la disposición de grandes mampuestos en la primera hilada de contacto sobre el mechinal, pero en este caso nos referimos concretamente a la disposición de pequeñas lajas sobre la parte superior del mechinal que actuaría de manera similar al ladrillo.

El sistema de encofrado reflejado por los medios auxiliares (cuerdas, tensores y puntales) apenas se detectan en este tramo. Los tensores para el arriostre de costales se observan en L-19. Por la posición conjunta a los mechinales, cabe plantear que la opción empleada responda al uso de clavos sujetando la aguja y cuerdas en la parte inferior del costal. Una o dos cuerdas ascienden en diagonal hacia la cara opuesta para atirantar el sistema mediante retorcimiento.

El revestimiento exterior o costra está muy alterado, dejando entrever el relleno del tapial. Algunas partes mantienen esta capa superficial que permite definir un recubrimiento del propio mortero de cal en el que se conservan las huellas de las tablas que conformaban el cajón (Fig. 14). Su degradación deja a la vista las piedras careadas como efecto de la pérdida de la costra. Donde se conserva su superficie, se observan algunas piedras derivado del vacío que generaba su ausencia de contacto con la madera del cajón. Este vacío impedía que penetrara el mortero, quedando a la vista tras la retirada del cajón.

Figura 13. Tipo de mechinal rectangular. Disposición de mampuestos en relación a algunos mechinales. Tensores para el arriostre el cajón
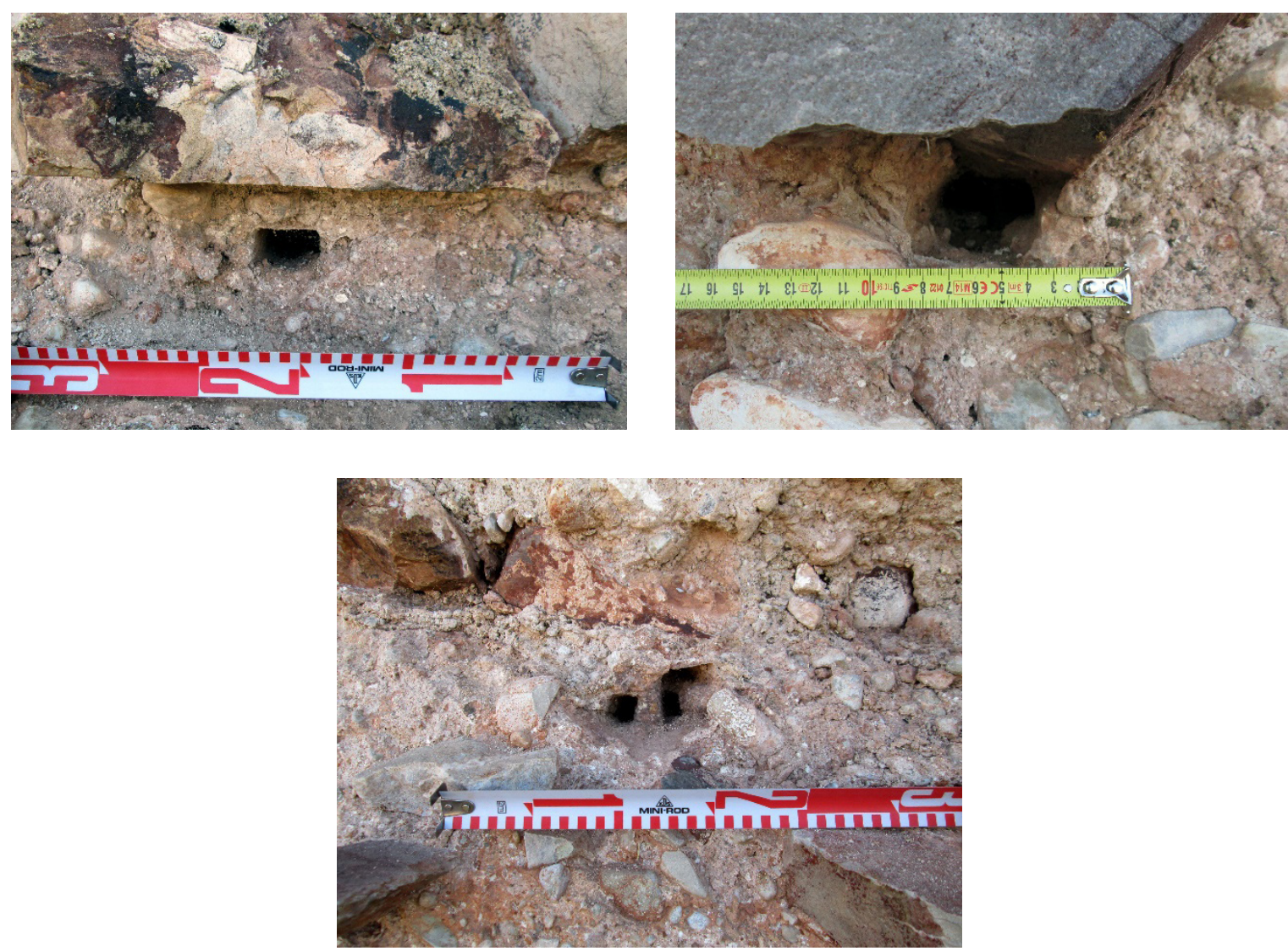

Fuente: fotografía de los autores. 
Figura 14. Superficie del tapial conservada en el interior de T-18

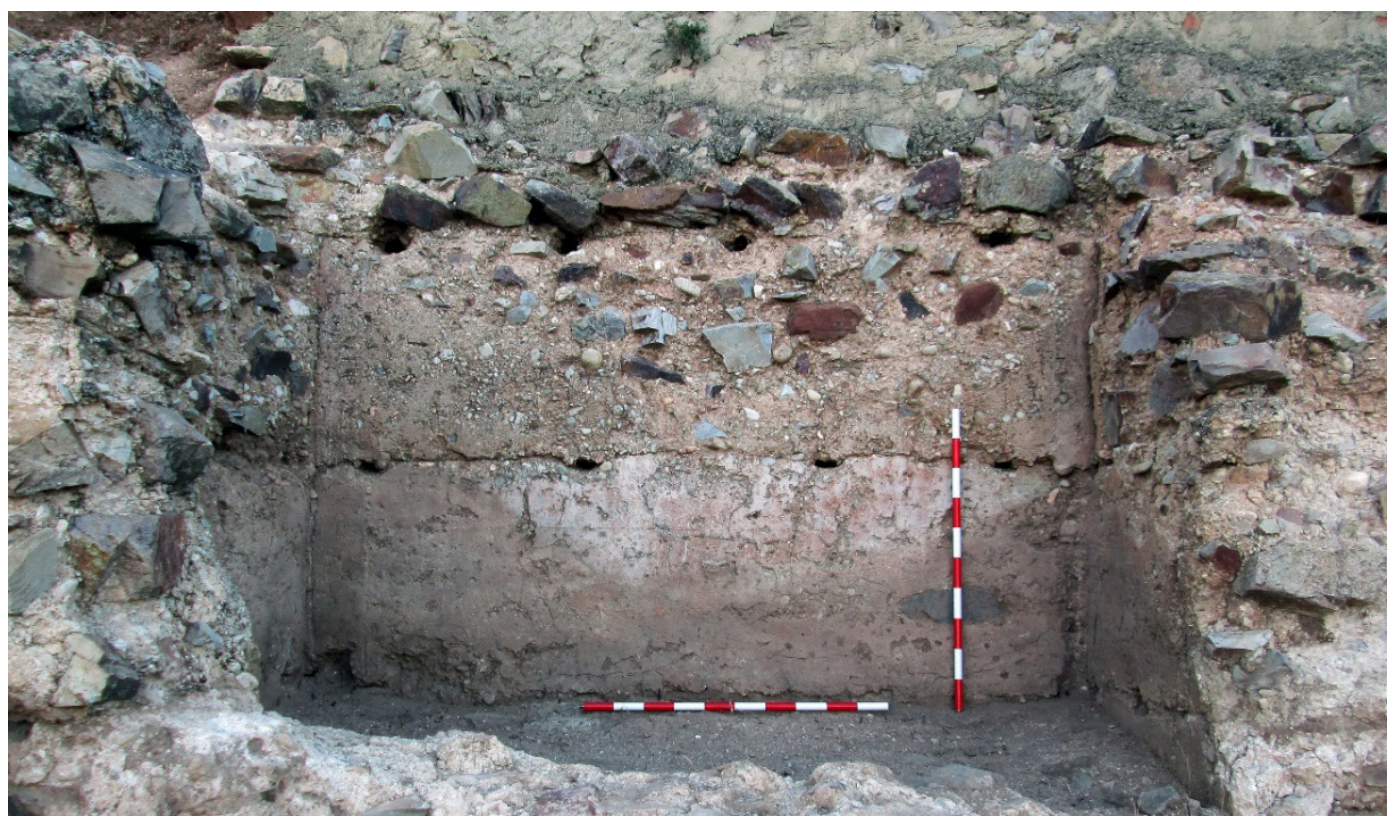

Fuente: fotografía de los autores.

Con respecto a las cimentaciones, no se constatan zócalos de mampostería para la nivelación apoyándose directamente el cajón sobre la roca del cerro como en el caso de la torre $\mathrm{T}-20^{9}$. Aunque para resolver esta cuestión se deberían de realizar sondeos arqueológicos que permitan alcanzar la base de la muralla de este tramo, siendo lo normal la presencia de zócalos de mampostería como cimentación.

Otro elemento a considerar es la documentación de lo que parece ser la impronta de un falso despiece de sillería (Fig. 15). Se trata de un estucado a base de líneas horizontales y verticales que enmascaraban los mechinales y las agujas como las juntas del encofrado, generando la imagen de un aparejo isodomo de grandes sillares, detalle decorativo que se observa en la esquina formada por L-20 y T-20. Este elemento se ha relacionado con la construcción, refortificación y ciertos aspectos propagandísticos llevados a cabo bajo el califato almohade (Azuar, 2004; Azuar y Ferreira, 2014; Azuar, Lozano, Llopis y Menéndez: 1996).

En la línea de unión entre la primera y segunda bancada de cajones, se observa parte de una acabado o faja horizontal que corresponde al dibujo de un "falso despiece de sillería" como tratamiento exterior. Se trata del primer caso en la provincia de Albacete documentado en una fortificación almohade ${ }^{10}$. Este elemento parece estar relacionado con una función estética y propagandística dentro de un programa ornamental de las fortificaciones del imperio almohade a partir del último tercio del siglo XII (Azuar y Ferreira, 2014: 403-405). Dentro de Castilla-La Mancha destacan los casos del castillo de Miraflores de Piedrabuena y algunos paños del alcázar de Calatrava la Vieja, ambos en la provincia de Ciudad Real.

9 La base de cajones de la torre T-20, que hace de unión entre los lienzos L-20 y L-21, se cimienta directamente sobre la base geológica. Este hecho lo ha puesto de manifiesto Gurriarán (2014: 283) para las construcciones almohades.

10 En la fortaleza de Taibilla (Nerpio) se observan estas fajas en los muros que configuran el recinto interior denominado "cortijo". Este elemento fue destacado en las descripciones de esta fortaleza (Simón, 2011: 466), aunque la construcción de este recinto se encaja dentro de las obras iniciadas por la encomienda de Santiago a partir de 1245 conjuntamente a la torre del homenaje. 
Figura 15. Documentación de la banda de estuco que definiría el posible falso despiece de sillares exterior. Línea de $10 \mathrm{~cm}$ de altura conservada en la esquina que conforma L20 y T20

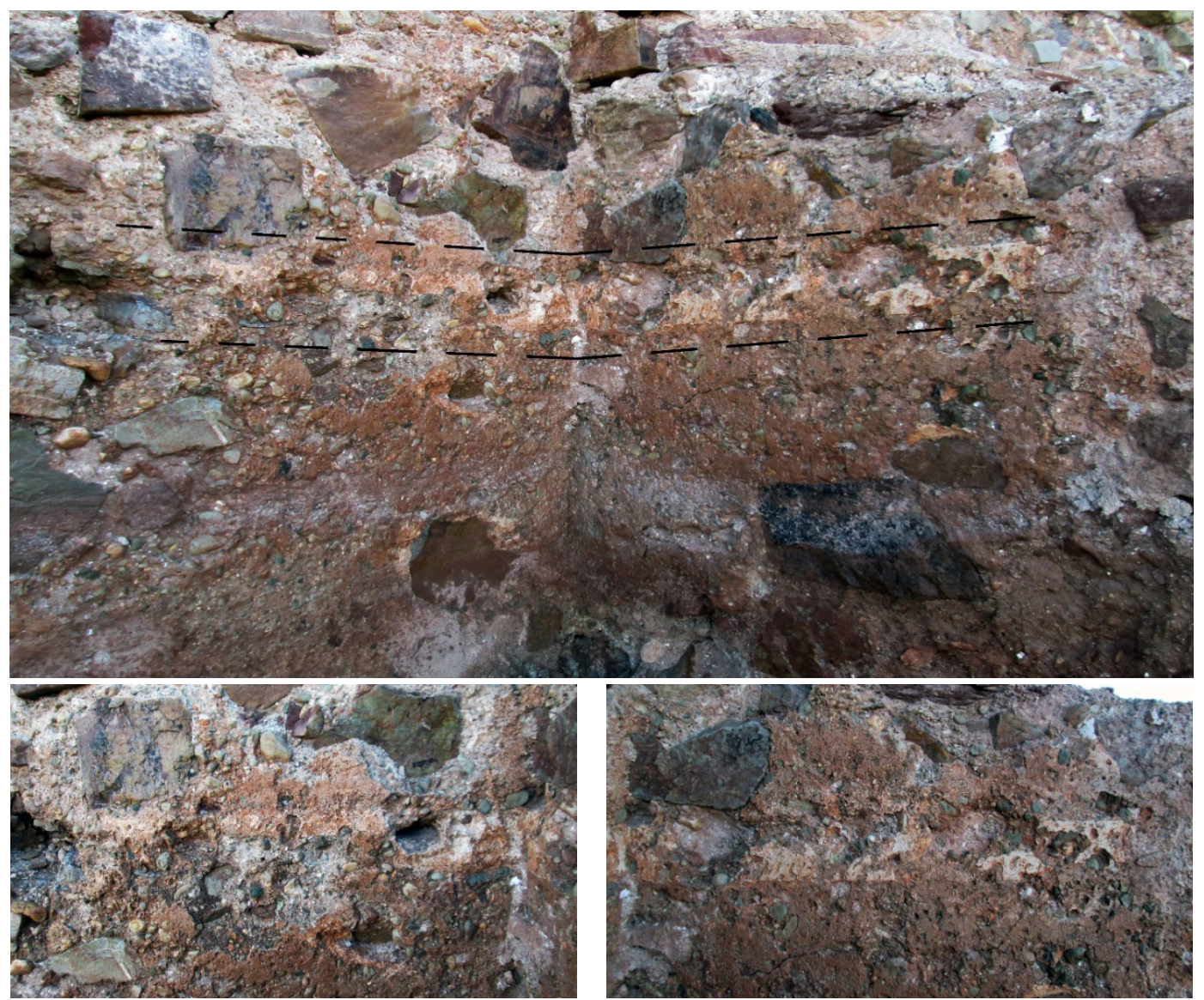

Fuente: fotografía de los autores.

Estas fortificaciones levantadas, ampliadas o rehechas y en las que aparece este desarrollo decorativo del "falso despiece de sillería", son una clara muestra de obras estatales que formarían parte del amplio y extenso programa defensivo de arquitectura militar ordenado y ejecutado bajo el gobierno del tercer califa almohade Abū Yūsuf Ya'qūb al-Mansūr, entre los años 1184 y 1199. Según las fuentes, el período en el que se levantaron la mayoría de las fortificaciones almohades en la Península se circunscribe a los últimos años del gobierno del califa Abū Yaqūb Yusūf y los de su hijo Abū Yusūf Ya'qūb al-Mansūr, es decir, entre los años 1170 y 1200 (Azuar y Ferreira, 2014: 410).

\section{CONCLUSIONES}

Los trabajos realizados parten de una primera valoración a partir de una inspección visual del recinto y de su superficie, junto al análisis paramental de uno de sus tramos. Lógicamente, consideramos este estudio una aportación inicial, a la espera de efectuar trabajos más intensivos y de excavación arqueológica, que permitan afianzar, confirmar o desmentir este primer balance que aquí presentamos.

Atendiendo a las fuentes escritas, a la diferenciación constructiva de las dos torres de la cima del cerro con respecto al resto del recinto de la fortificación dentro de la técnica del tapial y su disposición como una puerta, su origen estaría vinculado al dominio almorávide, tras la victoria de Tasufin para el control de la ruta entre Andalucía y el Levante. Sería un elemento dentro de una construcción basada en modelos ortogonales, heredera de la poliorcética califal, en una horquilla cronológica que consideramos entre 1125 y 1147, sobre 
la base de las fuentes históricas apuntadas en el apartado 2, que indican la presencia de esta fortaleza en estos años.

A inicios del siglo XII, con la implantación de los almorávides, se empiezan a desarrollar nuevos modelos de fortificación. Sirva como ejemplo la actual provincia de Jaén, territorio cercano al que estaba vinculado Alcaraz durante la etapa andalusí, donde se desarrollaron nuevas fortificaciones de estructura poligonal en las inmediaciones de tierras cultivables o en cruces de caminos (Quesada, 1996: 146).

A pesar de la escasez de datos arqueológicos que permitan dar una mayor precisión sobre su configuración, la fábrica de tapial hormigonado de las dos torres se puede relacionar con otras construcciones almorávides similares como las de Murcia, Almería, Sevilla, Córdoba o Niebla.

Figura 16. Restos de las dos torres del fortín almorávide en la cumbre del cerro

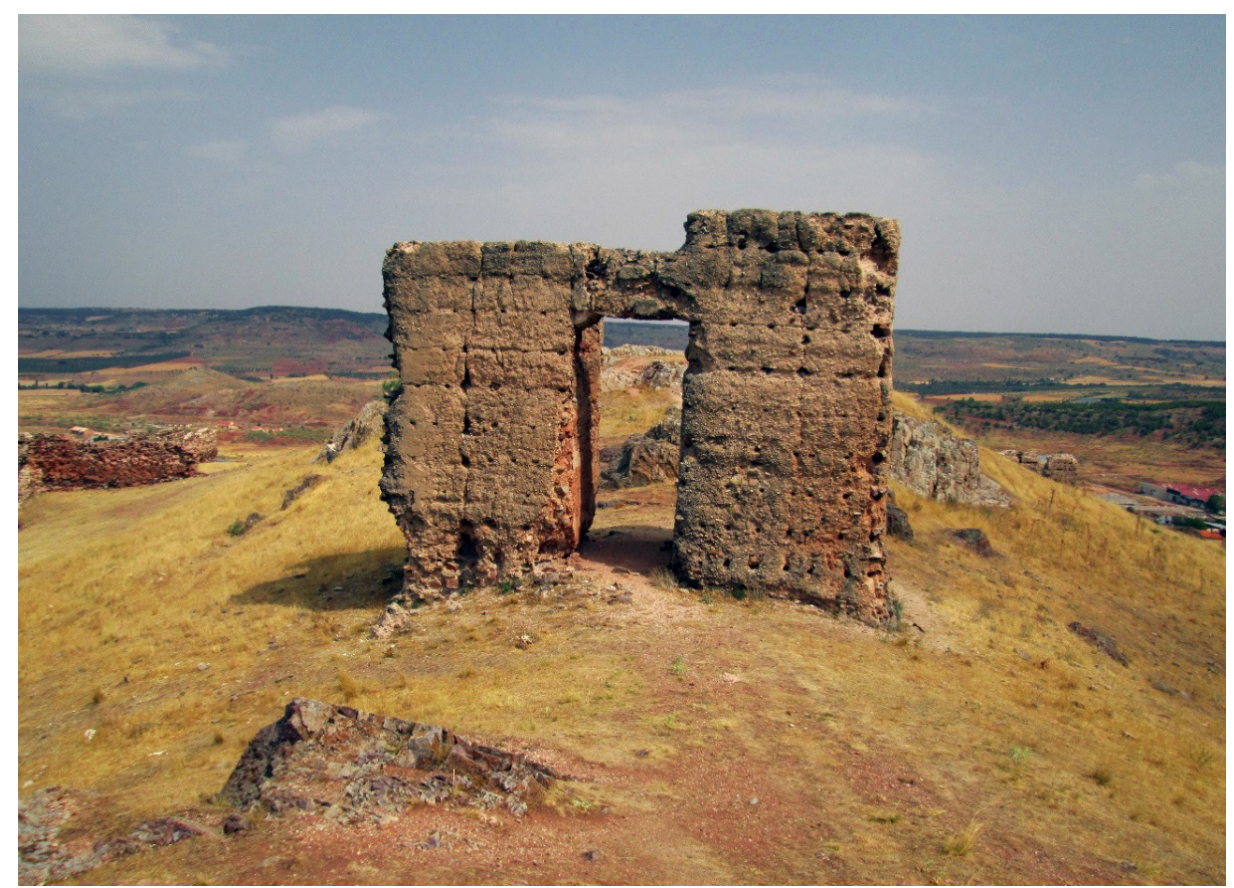

Fuente: fotografía de los autores.

El segundo recinto amurallado, lo interpretamos como una ampliación de esta fortificación primigenia, reflejando el diseño de una ciudadela-campamento (al-AskarRibat ${ }^{11}$. Durante el último cuarto del siglo XII se produce un proceso de refortificación, mediante la adecuación de antiguas fortalezas y construcción de nuevos emplazamientos, que afectó a los husun y a torres cercanas a ciudades y alquerías.

Es en estos años cuando el territorio de la provincia de Albacete, ante las avanzadillas castellanas, se transforma en una especie de marca defensiva (Tugur al-Kursi). Se generó una red defensiva, una frontera constituida por los almohades desde el momento de conquista de Murcia en 1172 ante el avance castellano por la Mancha Oriental, construyendo nuevas fortificaciones, aprovechando y reparando antiguas. Esta frontera estaría articulada entre Segura de la Sierra y Chinchilla, y compuesta por localidades como Yeste, Socovos, Férez, Alcaraz, Albacete y Peñas de San Pedro, actuando como una segunda línea defensiva, con otra situada en Alcalá de Júcar, como primera línea defensiva (Franco, 1997: 247).

11 Se trataría de un campamento militar planificado o fortaleza-campamento (al-Askar-Ribat) como ya apuntaron otros autores (Pavón, 1999: 125 y 188; Franco, 1997: 249). 
La construcción del segundo recinto de la fortaleza de Alcaraz, converge con un diseño planificado (Simón, 2011: 222) y un proceso constructivo ejecutado con premura como podemos observar en el análisis de su fábrica. Los elementos que se definen dentro de la poliorcética almohade se relacionan con los encontrados en el segundo recinto de Alcaraz: las torres esquineras y las torres en los frentes de muralla con un diseño implantado dentro de la dinámica fortificadora almohade ${ }^{12}$, restos del falso despiece de sillería, una antemuralla en la parte meridional y la puerta-torre de acceso en codo ${ }^{13}$. La presencia de todos estos elementos nos hace pensar en su vinculación con la política de fortificaciones del califa Abū Yā'qūb Yūsuf en la década de los setenta del siglo XII o del tercer califa almohade a partir de 1184.

Figura 17. Restos de la torre que configuraba la puerta de acceso
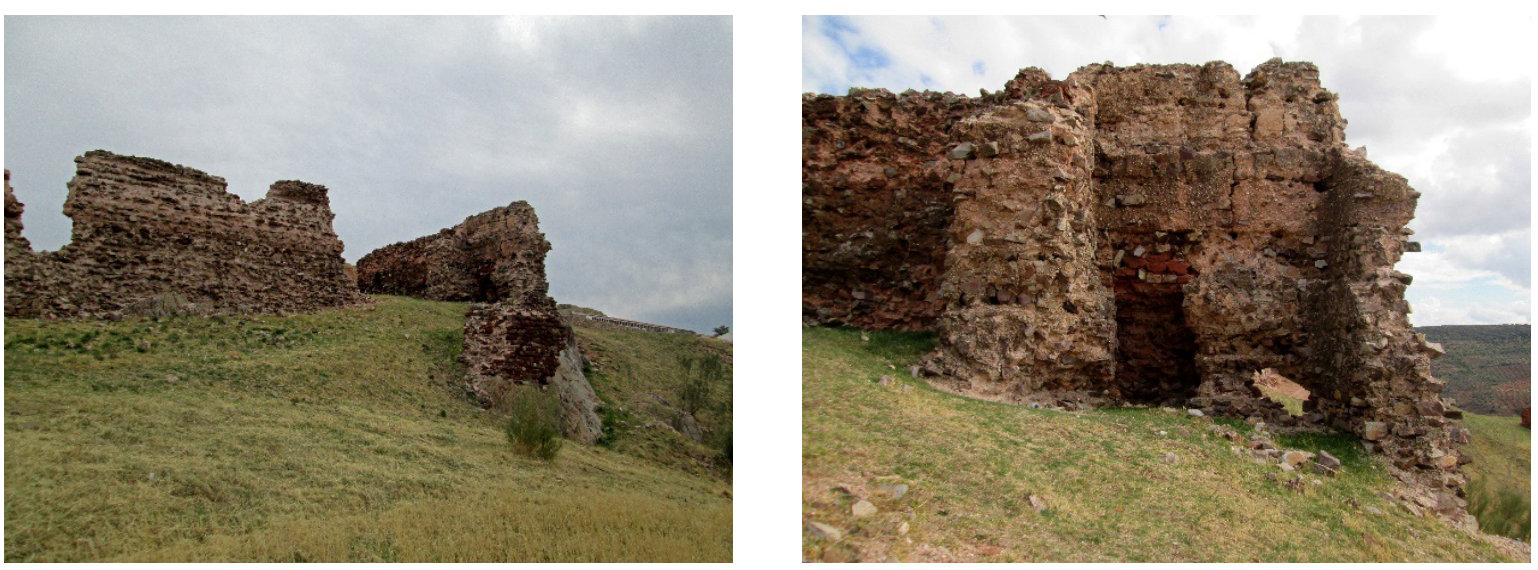

Fuente: fotografía de los autores.

Este segundo recinto cuenta con unas dimensiones de $210 \mathrm{~m}$. de longitud con una anchura de $94 \mathrm{~m}$. en su lado más corto y $140 \mathrm{~m}$. en su lado más largo, una superficie de $22.900 \mathrm{~m}^{2}$ (2'3 ha.) y $626 \mathrm{~m}$. de perímetro. Su desarrollo ortogonal va normalmente vinculado a programas constructivos previamente diseñados, a diferencia del poligonal que se establece en una clara adaptación al relieve del cerro en el que se inserta. Este diseño se observaría en la propia planta del recinto y en un ordenamiento de las torres en grupos de tres de los diferentes frentes. En el tramo estudiado, el esquema de tres torres consiste en una torre central de mayores dimensiones (7,35 $\mathrm{m}$. de frente), flanqueado por dos menores (4,5-5 m. de frente) $)^{14}$.

Sobre este tipo de campamentos, pocos son los datos que se tienen sobre su organización y configuración. En Córdoba destaca un recinto de 1 ha. al otro lado del río que rodeaba el acceso al puente y que se sospecha que dio amparo a las guarniciones antes de las campañas que el califa Abū Yā'qūb Yūsuf realizaría contra Toledo en 1171. A su vez, se constata otro recinto fortificado en las inmediaciones de Córdoba, en la Colina de los

12 Su diseño está muy en relación con los que se desarrollaron en las remodelaciones almohades de alcazabas urbanas como Sevilla, Córdoba, Jerez de la Frontera, Tarifa, Antequera, los alcázares de Écija o Gibraltar y en la construcción de fortines de ámbito rural vinculados a vías de comunicación. En estas remodelaciones y ampliaciones se observa un desarrollo poligonal con la disposición de frentes torreados y torres en los ángulos similar a los observados en el recinto de Alcaraz.

13 Las puertas en recodo se convierten en un rasgo de la edilicia almohade como algo habitual y también indica que las puertas flanqueadas por dos torres eran de tradición entre los almohades (Malpica, 1998: 329). 14 Las torres menores muestran una anchura de cajón de 1,15 m., mientras que la de mayor dimensión alcanza 1,32 m. de anchura de cajón. 
Quemados, a unos $300 \mathrm{~m}$. del alcázar, interpretado como un campamento militar en altura (León y Blanco, 2010; Blanco, 2014). El caso de Cáceres (Márquez y Gurriarán, 2003) es el que mejor se aproxima al de Alcaraz. Cuenta con una proyección ortogonal de la muralla y es identificada en las fuentes como madina o hisn, siendo su fundación una ciudadcampamento sobre una colina. Sigue el esquema de alcazaba, albacar y espacio urbano. Presenta antemuros y torres albarranas con un perímetro de $1.175 \mathrm{~m}$. y una superficie de 8,25 ha.

Figura 18. Hipótesis de la planta de la fortificación de Alcaraz en época almohade partir de los restos conservados y analizados durante los trabajos de campo de 2015

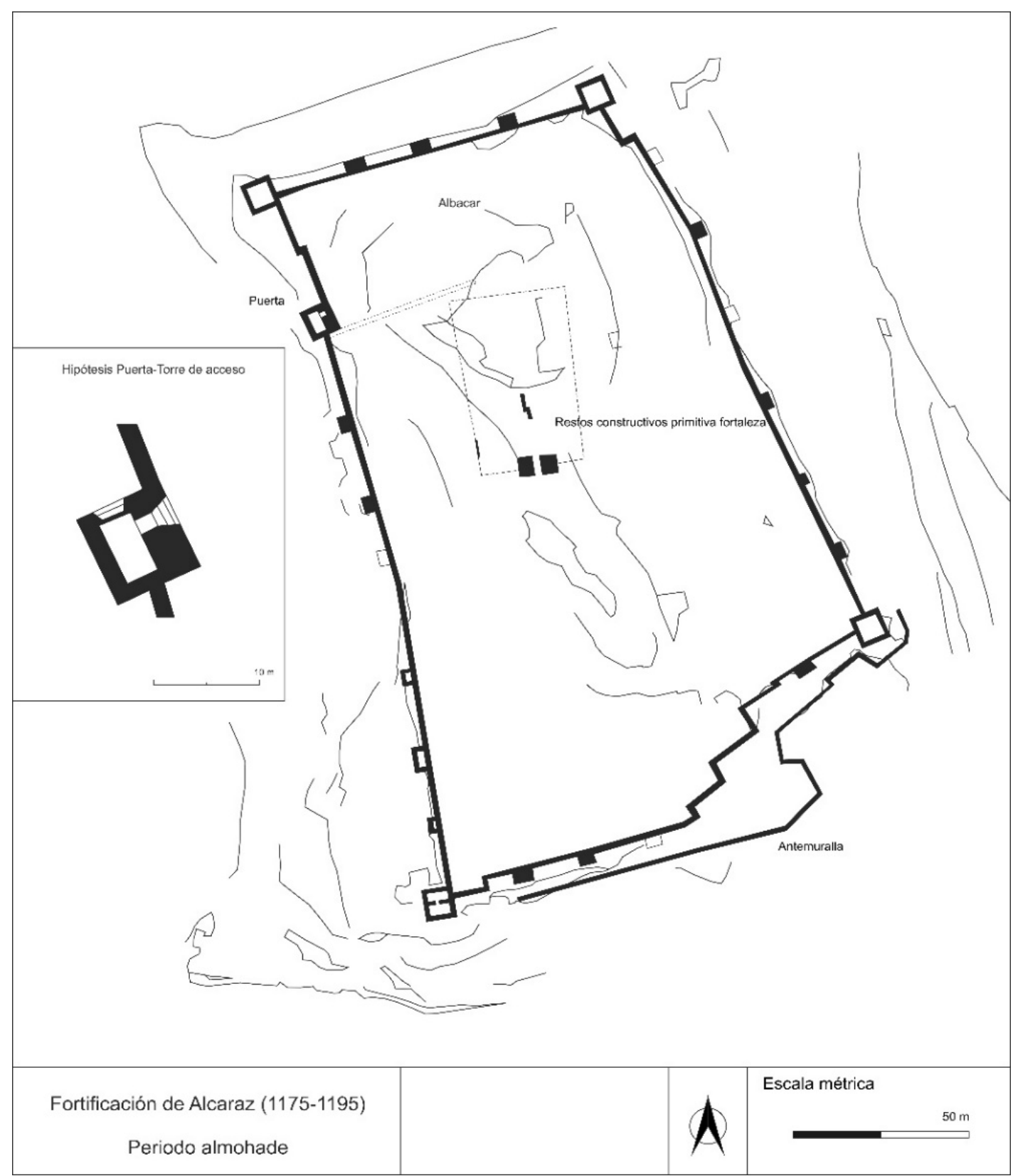

Fuente: elaboración propia. 
Sería necesario acometer actuaciones arqueológicas, principalmente en la ladera sur y este, y en el interior del recinto para determinar el tipo de poblamiento y su evolución y observar la configuración real de este emplazamiento. El propio conjunto se organizaría aprovechando la fortaleza en la cúspide, una celloquia o un alcázar que aprovecharía la infraestructura previa. Queda por determinar la evolución interna que sufrió durante este periodo de dominio almohade hasta que finalmente quedó en manos castellanas. Pero no sólo este aspecto, ya que la relación con el territorio y los sistemas de explotación del mismo supone una cuestión a abordar en trabajos de futuro. En definitiva, un análisis más pormenorizado de los sistemas agrarios y de la relación de la red de alquerías o de yacimientos de su entorno, sería lo oportuno para tener un mayor conocimiento de esta fortificación y de su poblamiento.

\section{BIBLIOGRAFÍA}

Acién Almansa, M. P. (1995): "La fortificación en Al-Andalus”, Archeologia Medievale, 22, 7-36.

Amador de los Ríos, R. (1917): Catálogo de los monumentos históricos artísticos de la provincia de Albacete, Madrid.

Azuar Ruiz, R. (1995): "Las técnicas constructivas en al-Andalus. El origen de la sillería y del hormigón de tapial", en Iglesia Duarte, J. I (coord.), V Semana de Estudios Medievales, Nájera, Instituto de Estudios Riojanos, 125-142.

- (2004): "Técnicas constructivas y fortificación almohade en al-Andalus", en Ramírez del Río, J., Valor Piechotta, M y Villar Iglesias, J. L. (coords.), Los Almohades. Su patrimonio arquitectónico y arqueológico en el sur de al-Andalus, Sevilla, Junta de Andalucía, 57-74.

Azuar, R. y Ferreira Fernandes, I. C. (2014): "La fortificación del califato almohade", en Cressier, P. y Salvatierra Cuenca, V. (coords.), Las Navas de Tolosa (1212-2012). Miradas Cruzadas, Jaén, Universidad de Jaén, 395-420.

Azuar Ruiz, R., Lozano Olivares, F. J., Llopis García, T. M. y Menéndez Fueyo, J. L. (1996): "El falso despiece de sillería en las fortificaciones de tapial de época almohade en alÁndalus", Estudios de Historia y Arqueología Medievales, 11, 245-278.

Bazzana, A. (2009): "Castillos y sociedad en al-Andalus: cuestiones metodológicas y líneas actuales de investigación”, en Molina Molina, A. L. y Eiroa Rodríguez, J. A. (eds.), El castillo medieval en tiempos de Alfonso X El Sabio, Murcia, Universidad de Murcia, 9-40.

Bazzana, A., Cressier, P. y Guichard, P. (1988): Châteaux ruraux d'al-Andalus. Histoire et archéologie des husûn du Sud-Est de l'Espagne, Madrid, Casa de Velázquez.

Blanco Guzmán, R. (2014): "Córdoba y el califato almohade, una lectura arqueológica", en Cressier, P. y Salvatierra Cuenca, V. (coords.), Las Navas de Tolosa (1212-2012). Miradas Cruzadas, Jaén, Universidad de Jaén, 499-508.

Canivell, J. y Graciani García, A. (2015): "Caracterización constructiva de las fábricas de tapia en las fortificaciones almohades del antiguo Reino de Sevilla", Arqueología de la Arquitectura, 12, e025.

Cara Barrionuevo, L. y Rodríguez López, J. M. (1998): "Introducción al estudio cronotipológico de los castillos almerienses", en Malpica Cuello, A. (coord.), Castillos y territorio en al-Andalus, Granada, Athos-Pérgamo, 164-245.

Cobos Guerra, F., Castro Fernández, J. J. y Canal Arribas, R. (2012): Castros y recintos de la frontera de León en los siglos XII y XIII. Fortificaciones de tapial de cal y canto o mampostería encofrada. Valladolid, Junta de Castilla y León.

Franco Sánchez, F. (1997): "La frontera alternativa: vías y enfrentamientos islamo-cristianos 
en la Mancha Oriental y Murcia", en Segura Artero, P. (coord.), Actas del Congreso la Frontera Oriental Nazarí como Sujeto Histórico (S. XIII-XVI), Almería, Instituto de Estudios Almerienses, 237-252.

Frey Sánchez, A. V. (2009): “¿Un castillo omeya en Moratalla? Estudio arquitectónico y contextualización del castillo de Priego (Moratalla, Murcia)", Tudmir, 1, 41-52.

- (2014): Castillos y territorios de Alto Segura. Arquitectura defensiva y poblamiento entre los siglos XII y XIV. Murcia, Ediciones Tres Fronteras.

Gallego Valle, D., Molero García, J., Castilla Pascual, F. J., Peña Ruiz, C. y Sanz Martínez, D. (2016): "El uso del tapial en las fortificaciones medievales de Castilla-La Mancha: propuesta de estudio y primeros resultados de la investigación", en Gil Crespo, I. (ed.), Actas de las Segundas Jornadas sobre Historia, arquitectura y construcción fortificada. Madrid, Instituto Juan de Herrera, 215-234.

Gil Crespo, I. J. (2015): Fundamentos constructivos de las fortificaciones fronterizas entre las coronas de Castilla y Aragón de los siglos XII al XV en la actual provincia de Soria. Madrid, Ministerio de Defensa.

Gil Crespo, I. J. y Maldonado Ramos, L. (2015): "Hacia una taxonomía constructiva de las tapias de tierra y fábricas encofradas históricas", Informes de la Construcción, 67 (538), e036.

Graciani García, A. y Tabales Rodríguez, M. A. (2008): "El tapial en el área sevillana. Avance cronológico estructural", Arqueología de la Arquitectura, 5, 135-158.

Gurriarán Daza, P. (2014): "Las técnicas constructivas en las fortificaciones andalusíes", en Sabaté, F. y Brufal, J. (dirs.), La Ciutat Medieval i Arqueologia. Lérida, Pagés editors, 263-292.

- (2016): "Tapias, tapiales y arquitectos. Reflexiones sobre las restauraciones de tierra y cal", en García Porras, A. (ed.), Arqueología Medieval y Restauración, Granada, Alhulia, 127-152.

Gurriarán Daza, P. y Sáez Rodríguez, A. J. (2002): "Tapial o fábricas encofradas en recintos urbanos andalusíes", en Actas del II Congreso Internacional: La ciudad en al-Analus y el Magreb, Granada, Fundación El Legado Andalusí, 561-625.

León Muñoz, A. y Blanco, R. (2010): "La Fitna y sus consecuencias. La revitalización urbana de Córdoba en época almohade", en Vaquerizo, D. y Murillo, J. F. (eds.), El anfiteatro romano de Córdoba y su entorno urbano. Análisis arqueológico (ss. I-XIII d. C.), Monografías de Arqueología Cordobesa, 19, Córdoba, Universidad de Córdoba, 699-726.

Malpica Cuello, A. (1998): "Las técnicas constructivas en al-Andalus. Un debate entre la Arqueología y la Arquitectura”, en Vaquero Díaz, M. B., Pérez Rodríguez, F. J. y Durany Castrillo, M. (coords.), Técnicas agrícolas, industriais e constructivas na Idade Media, Vigo, Universidad de Vigo, 277-336.

- (2009): "Castillos, alquerías y ciudades en al-Andalus. Un debate partiendo del análisis arqueológico", en Molina Molina, A. L. y Eiroa Rodríguez, J. A. (eds.), El castillo medieval en tiempos de Alfonso X El Sabio, Murcia, Universidad de Murcia, 99-120.

Márquez Bueno, S. y Gurriarán Daza, P. (2003): "La muralla almohade de Cáceres: aspectos constructivos, formales y funcionales", Arqueología y Territorio Medieval, 10.1, 57-118.

- (2008): "Recursos formales y constructivos en la arquitectura militar almohade de alAndalus", Arqueología de la Arquitectura, 5, 115-134.

- (2012): "Tras las huellas de los almohades. Reflexiones sobre las últimas fortificaciones del Badajoz andalusí", Cuadernos de Arquitectura y Fortificación, 0, 55-76.

- (2017): "El recinto almohade de Cáceres: nuevas aportaciones", Arqueología y Territorio Medieval, 24, 207-228. 
Martín Civantos, J. M. (2001-2002): "Ensayo de análisis comparativo de técnicas, materiales y tipos constructivos en las fortificaciones medievales del Zenete (Granada)", Miscelánea Medieval Murciana, 25-26, 182-220.

- (2009): "Ensayo de sistematización de las técnicas constructivas andalusíes de la provincia de Granada", en Sabaté, F. (dir), Arqueologia medieval. La transformació de la frontera medieval musulmana, Lérida, Pagès editors, 119-152.

Martínez Enamorado, V. (1998): "La terminología castral en el territorio de Ibn Hafsun", en Actas I Congreso Internacional fortificaciones en al-Andalus, Algeciras, Ayuntamiento de Algeciras, 33-78.

Mileto, C., Vegas López-Manzanares, F. y García Soriano, L. (2013): "La técnica constructiva de la tapia en la arquitectura militar y defensiva en España. Variantes e invariantes", en Huerta, S. y López Ulloa, F., Actas del VIII Congreso Nacional de Historia de la Construcción, Madrid, Instituto Juan de Herrera, 681-687.

Molero García, J., Arcos Domínguez, M. C. y Molina Cañadas, M. (2014): "Vigilar caminos, defender la frontera: la fortaleza almohade de Miraflores (Piedrabuena, Ciudad Real)", en Cressier, P. y Salvatierra Cuenca, V. (coords.), Las Navas de Tolosa (1212-2012). Miradas Cruzadas, Jaén, Universidad de Jaén, 577-591.

Navarro Palazón, J. y Jiménez Castillo, P. (2011): "Materiales y técnicas constructivas en la Murcia andalusí (siglos X-XIII)", Arqueología de la Arquitectura. 8, 85-120.

Pacheco Paniagua, J. A. (1981): "El castillo de Alcaraz en la obra del geógrafo musulmán Al-Himyari, (S. XV)", Al-Basit. 10, 73-84.

Pavón Maldonado, B. (1999): Tratado de arquitectura hispanomusulmana, II. Castillos y fortalezas, Madrid, CSIC.

Pérez de Pareja, E. (1740): Historia de la primera fundación de Alcaraz y milagroso aparecimiento de la Nuestra Señora de Cortes, Valencia.

Pretel Marín, A. (2004): "Despoblados y pueblas medievales en las sierras de Riópar, El Pozo y Alcaraz", en Homenaje a Miguel Rodríguez Llopis, Albacete, Instituto de Estudios Albacetenses, 233-282.

- (2008): Alcaraz y su tierra en el siglo XIII. Albacete, Instituto de Estudios Albacetenses.

- (2013): "La herencia de Mentesa: ¿Rebeldes y mozárabes en tierras de Alcaraz de 711 a 1213?", en Pretel Marín, A. (coord.), Alcaraz, del Islam al concejo castellano, Alcaraz, Instituto de Estudios Albacetenses, 11-54.

- (2014): "La toma de Alcaraz, secuela y colofón del triunfo de las Navas", en Estepa Díez, C. y Carmona Ruíz, M. A. (coords.), La Península Ibérica en tiempos de las Navas de Tolosa, Monografías de la Sociedad de Estudios Medievales, núm. 5, Madrid, Sociedad Española de Estudios Medievales, 283-299.

- (2015): "Del Islam a la villa castellana", en Alcaraz y su alfoz. El testimonio del tiempo. Medio Natural, Historia y Patrimonio Cultural. Albacete, Ecomuseo, 85-136.

Quesada Quesada, T. (1996): "Poblamiento y fortificación del territorio en los siglos XII-XIII. El caso de las sierras meridionales de Jaén", Malpica Cuello, A. (coord.), Castillos y territorio en al-Andalus, Granada, Athos-Pérgamo, 141-163.

Simón García, J. L. (2011): Castillo y torres de Albacete, Albacete, IEA.

- (2013): "Del Hisn al-Karas al Castrum de Alcaraz: una aproximación desde la arqueología", en Pretel Marín, A. (coord.), Alcaraz, del Islam al concejo castellano, Alcaraz, Instituto de Estudios Albacetenses, 55-76.

- (2015): "La fortaleza de Alcaraz", en Alcaraz y su alfoz. El testimonio del tiempo Medio Natural, Historia y Patrimonio Cultural, Albacete, Ecomuseo, 71-84.

Simón García, J. L. y Hernández Carrión, E. (2016): "Ciudades perdidas/ciudades encontradas: El Santo de Alcaraz". Zahora. Revista de Tradiciones Populares, 62, 9-125. 
Simón García, J. L. y Segura Herrero, G. (2011): "El poblamiento tardoantiguo y emiral en la sierra de Alcaraz (Albacete)", Antigüedad y Cristianismo, 28, 327-353.

Soler Estrella, A. (2009): "La técnica del tapial en las fortificaciones y despoblados en Sharq al-Andalus. Un estudio- arquitectónico constructivo", en Huerta, S., Marín, R., Soler, R y Zaragozá, A. (coords.), Actas del VI Congreso Nacional de Historia de la Construcción, Madrid, Instituto Juan de Herrera, 1361-1370.

Torremocha Silva, A. (2004): "Fortificaciones almohades en la provincia de Cádiz", en Valor Piechotta, M., Villar Iglesias, J. L. y Ramírez del Río, J. (coords.), Los Almohades. Su patrimonio arquitectónico y arqueológico en el sur de al-Andalus, Sevilla, Junta de Andalucía, 103-121.

Torres Balbás, L. (1976): “Arte Hispano-musulmán”, en Historia de España de Menéndez Pidal, vol. V, Madrid, Espasa-Calpe.

Vallvé Bermejo, J. (1976): "Notas de metrología hispano-árabe. El codo en la España musulmana", Al-Andalus, 41, 2, 339-354. 